\title{
Contribution of NtZIP1-Like to the Regulation of Zn Homeostasis
}

\author{
Anna Papierniak' ${ }^{1}$ Katarzyna Kozak ${ }^{1}$, Maria Kendziorek ${ }^{1}$, Anna Barabasz', \\ Małgorzata Palusińska ${ }^{1}$, Jerzy Tiuryn ${ }^{2}$, Bohdan Paterczyk ${ }^{3}$, Lorraine E. Williams ${ }^{4}$ and \\ Danuta M. Antosiewicz ${ }^{1 *}$
}

\begin{abstract}
1 Institute of Experimental Plant Biology and Biotechnology, Faculty of Biology, University of Warsaw, Warsaw, Poland, ${ }^{2}$ Faculty of Mathematics, Informatics, and Mechanics, University of Warsaw, Warsaw, Poland, ${ }^{3}$ Laboratory of Electron and Confocal Microscopy, Faculty of Biology, University of Warsaw, Warsaw, Poland, ${ }^{4}$ Biological Sciences, University of Southampton, Southampton, United Kingdom
\end{abstract}

Tobacco has frequently been suggested as a candidate plant species for use in phytoremediation of metal contaminated soil but knowledge on the regulation of its metal-homeostasis is still in the infancy. To identify new tobacco metal transport genes that are involved in $\mathrm{Zn}$ homeostasis a bioinformatics study using the tobacco genome information together with expression analysis was performed. Ten new tobacco metal transport genes from the ZIP, NRAMP, MTP, and MRP/ABCC families were identified with expression levels in leaves that were modified by exposure to Zn excess. Following exposure to high Zn there was upregulation of NtZIP11-like, NtNRAMP3, three isoforms of NtMTP2, three MRP/ABCC genes (NtMRP5-like, NtMRP10-like, and NtMRP14 like) and downregulation of NtZIP1-like and NtZIP4. This suggests their involvement in several processes governing the response to Zn-related stress and in the efficiency of $\mathrm{Zn}$ accumulation (uptake, sequestration, and redistribution). Further detailed analysis of NtZIP1-like provided evidence that it is localized at the plasma membrane and is involved in Zn but not Fe and Cd transport. NtZIP1-like is expressed in the roots and shoots, and is regulated developmentally and in a tissue-specific manner. It is highly upregulated by $\mathrm{Zn}$ deficiency in the leaves and the root basal region but not in the root apical zone (region of maturation and absorption containing root hairs). Thus NtZIP1-like is unlikely to be responsible for $\mathrm{Zn}$ uptake by the root apical region but rather in the uptake by root cells within the already mature basal zone. It is downregulated by Zn excess suggesting it is involved in a mechanism to protect the root and leaf cells from accumulating excess $\mathrm{Zn}$.

Keywords: zinc, tobacco, ZIP, NtZIP1-like, yeast complementation

\section{INTRODUCTION}

Tobacco (Nicotiana tabacum L cv. Xanthi) has frequently been considered for phytoremediation purposes because of its high biomass and ability to take up and accumulate in leaves high amounts of metals, including zinc (Zn) (Vangronsveld et al., 2009; Herzig et al., 2014; VeraEstrella et al., 2017). To improve its capacity to take up and store metals in shoots, it has been transformed with a number of metal homeostasis genes, but with limited success (Gisbert et al., 2003; Martínez et al., 2006; Gorinova et al., 2007; Wojas et al., 2008, 2009; Korenkov et al., 2009; Siemianowski et al., 2011; Barabasz et al., 2013; Wang et al., 2015). Recently, it was shown that when expressing metal transporters to engineer new metal-related traits, a major 
part of the resulting phenotype was due to the modulation of endogenous gene expression (Barabasz et al., 2016; Kendziorek et al., 2016). Therefore, a greater understanding of $\mathrm{Zn}$-homeostasis mechanisms is required to successfully genetically modify the efficiency of $\mathrm{Zn}$ accumulation in shoots. Maintaining high $\mathrm{Zn}$ in the above ground organs depends on three major processes operating efficiently: Zn uptake from the soil, root-to-shoot translocation and storage in leaves without detrimental toxic effects.

$\mathrm{Zn}$ uptake is thought to be mediated primarily by ZIP (ZRT $\backslash$ IRT related Protein) metal transporters. In Arabidopsis thaliana AtZIP2, AtIRT1 and AtIRT3 residing in the plasma membrane have been identified as key players in $\mathrm{Zn}$ acquisition by roots (Vert et al., 2002; Lin et al., 2009; Palmer and Guerinot, 2009; Milner et al., 2013). The root-to-shoot translocation of $\mathrm{Zn}$ (and other metals) depends on two main factors: the ability to store the metal in the roots; and the efficiency of its loading into xylem vessels. It has been shown that HMAs (Heavy-Metal ATPases) which belong to the $\mathrm{P}_{1 \mathrm{~B}}$-ATPase family (Williams et al., 2000; Williams and Mills, 2005) are involved in both processes. HMA3, identified in A. thaliana and rice, localized in the tonoplast of root cortical cells, limits translocation of $\mathrm{Cd}$ from the roots to the shoots by sequestrating the metal into the root vacuoles. There is a suggestion that it could also transport $\mathrm{Zn}$ into the vacuoles and control the amount of $\mathrm{Zn}$ available for xylem loading and thus the efficiency of its translocation to the shoot (Morel et al., 2009; Ueno et al., 2010; Miyadate et al., 2011). The efficiency of the next step in $\mathrm{Zn}$ translocation to shoots - loading of a metal into the xylem vessels, is under the control of two genes with overlapping function, HMA2 and HMA4 (Hussain et al., 2004; Verret et al., 2004; Wong and Cobbett, 2009). Encoded proteins are localized in the roots at the plasma membrane of xylem parenchyma cells where they are responsible for $\mathrm{Zn}$ (and also Cd) efflux to the xylem. Decreased translocation of $\mathrm{Zn}$ to shoots in the athma2athma4 double mutant led to severe $\mathrm{Zn}$ deficiency (Hussain et al., 2004; Wong and Cobbett, 2009; Mills et al., 2012).

$\mathrm{Zn}$ transported to the shoots is stored primarily in the mesophyll cells of leaves. Its level of accumulation depends on the ability of the mesophyll cells to store the metal without toxicity. This complex process involves efficient metal import and its loading into the vacuoles, but also regulated redistribution from this compartment. Currently we are far from having a clear picture of all the elements involved. The potential players include members of several transport families. The ZIP genes play a diverse roles, and those present in the plasma membrane are responsible for $\mathrm{Zn}$ uptake, while others localized in the tonoplast could contribute to control of $\mathrm{Zn}$ release from vacuoles (Guerinot, 2000; Milner et al., 2013; Ricachenevsky et al., 2015). Accumulation of metal/s in the vacuoles also depends on the NRAMP (Natural Resistance-Associated Macrophage Protein) family. Members of this family transport $\mathrm{Fe}$ and $\mathrm{Mn}$, while $\mathrm{Cd}, \mathrm{Zn}$ or $\mathrm{Ni}$ can also serve as substrates for some (Nevo and Nelson, 2006; Ricachenevsky et al., 2015). AtNRAMP1 is a plasma membrane $\mathrm{Mn}$ uptake system in roots of $A$. thaliana; Cailliatte et al. (2010), while NRAMP3 and NRAMP4 are involved in metal release ( $\mathrm{Mn}$ and $\mathrm{Fe}$ ) from vacuoles in leaves and seeds (Lanquar et al., 2005, 2010). High expression of NRAMP3 and NRAMP4 genes was noted in the leaves of $\mathrm{Zn} / \mathrm{Cd}$ hyperaccumulating A. halleri (Weber et al., 2004) and Thlaspi caerulescens. Both TcNRAMP3 and TcNRAMP4 were implicated in metal hypertolerance, but the precise role is yet to be determined (Oomen et al., 2009). Loading of metals into vacuoles is provided by the members of the MTP (Metal Tolerance Proteins) family. Residing in the tonoplast, they are involved in sequestration primarily $\mathrm{Zn}$ in the vacuoles, but other metals such as $\mathrm{Fe}, \mathrm{Mn}, \mathrm{Cd}, \mathrm{Ni}$ or $\mathrm{Co}$ can also be substrates for some family members (Gustin et al., 2011; Menguer et al., 2013; Ricachenevsky et al., 2013; Farthing et al., 2017). However, some MTPs are localized in the plasma membrane, and they remove cations from the cytoplasm to the cell wall (Menguer et al., 2013; Migocka et al., 2015). In the leaves, a key protein for $\mathrm{Zn}$ sequestration and detoxification is the vacuolar protein MTP1. AtMTP1 from A thaliana contributes to $\mathrm{Zn}$ accumulation in leaves and to basal $\mathrm{Zn}$ tolerance by sequestering $\mathrm{Zn}$ in vacuoles (Kobae et al., 2004; Desbrosses-Fonrouge et al., 2005; Ricachenevsky et al., 2013). MTP1 also has a function in $\mathrm{Zn}$ accumulation in shoots of $\mathrm{Zn}$ hyperaccumulators such as A. halleri (Dräger et al., 2004) or Thlaspi goesingense (Gustin et al., 2009).

Despite a broad interest in the use of tobacco to remove metals from contaminated soil, knowledge of the metal homeostatic processes in this species is still in its infancy. Only a few metal transport genes have been cloned and characterized so far. NtPDR3 (pleiotropic drug resistance) from Nicotiana tabacum was shown to be highly expressed under Fe-deficiency conditions suggesting its involvement in iron homeostasis (Ducos et al., 2005). MTP family members involved in $\mathrm{Zn}$ and Co metabolism were cloned from Nicotiana tabacum (NtMTP1a, NtMTP1b) and Nicotiana glauca (NgMTP1) (Shingu et al., 2005). Also, two orthologs of the Arabidopsis thaliana HMA2 and HMA4 were identified in tobacco, NtHMA $\alpha$ and $N t H M A \beta$. Similar to Arabidopsis genes, NtHMA $\alpha$ and NtHMA $\beta$ are responsible for $\mathrm{Zn}$ and Cd root-to-shoot translocation (Hermand et al., 2014; Liedschulte et al., 2017). Furthermore, studies performed on tobacco BY-2 cells identified two genes encoding Fe uptake proteins; NtNRAMP3 and NtZIP1 (Sano et al., 2012). A second ZIP family member from tobacco, NtIRT1, was also shown to transport $\mathrm{Fe}$, and its expression depended on the level of Fe and $\mathrm{Cd}$ in the medium (Yoshihara et al., 2006; Hodoshima et al., 2007).

To learn more about the molecular mechanism regulating $\mathrm{Zn}$ accumulation in tobacco leaves, the aim of this study was to identify the members of the following key metal transport families that could be involved in regulating $\mathrm{Zn}$ levels in the leaf blades: ZIP, NRAMP, and MTP. Moreover, taking into account very limited knowledge on the possible contribution of MRPs (multidrug resistance-associated proteins) family members to detoxification of metals, they were also included. MRP/ABCC (Klein et al., 2006; Verrier et al., 2008) transporters are a ubiquitous subfamily of ABC (ATP Binding Casette) transporters which catalyze the export of substrates out of the cytosol in an ATP-dependent manner. Their involvement in $\mathrm{Zn}$ and $\mathrm{Cd}$ hypertolerance in $N$. caerulescens was shown by Halimaa et al. 
(2014) and also in the detoxification of Cd (Bovet et al., 2003, 2005; Wojas et al., 2007; Gaillard et al., 2008).

The major focus in this study was on proteins mediating $\mathrm{Zn}$ import into the tobacco leaf cells from the ZIP family. They were identified and initially characterized in several organisms, for example in Arabidopsis (15 ZIPs; Grotz and Guerinot, 2006), rice (16 ZIPs; Chen et al., 2008), bean (23 ZIPs; Astudillo et al., 2013) and more recently, wheat (Evens et al., 2017). In addition to $\mathrm{Zn}$, ZIPs mediate transport of $\mathrm{Mn}, \mathrm{Fe}, \mathrm{Ni}$, or $\mathrm{Cu}$. Detailed analysis of the role of ZIP genes is still lacking for many of those identified. Their function has been anticipated primarily based on metalspecific ( $\mathrm{Zn}, \mathrm{Fe}, \mathrm{Mn}, \mathrm{Cd}$, and $\mathrm{Cu}$ ) and concentration-dependent (deficit/sufficient/excess) regulation of ZIP expression in organs. (Bashir et al., 2012; Sinclair and Krämer, 2012; Milner et al., 2013; Evens et al., 2017; Nazri et al., 2017).

Here, bioinformatics analysis of tobacco genome data was performed to identify sequences homologous to chosen Arabidopsis thaliana metal transport genes, and subsequent expression analysis led to the identification of the NtZIP1-like. It was cloned and characterized indicating its specific function in the regulation of $\mathrm{Zn}$ homeostasis in tobacco leaves.

\section{MATERIALS AND METHODS}

\section{Plant Material and Growth Conditions}

All experiments were performed on tobacco plants (Nicotiana tabacum var. Xanthi). Surface sterilized seeds ( $8 \%$ sodium hypochloride $\mathrm{w} / \mathrm{v}$ for $2 \mathrm{~min}$ ) were germinated on Petri dishes positioned vertically containing quarter-strength Knop's medium, 2\% sucrose (w/v) and 1\% agar (w/v) (Barabasz et al., 2013). Three weeks following germination, seedlings were transferred to hydroponic conditions. They were cultivated in 2-L pots (5 plants per pot) on aerated quarter-strength Knop's medium for 2 weeks to allow them to adjust to hydroponic conditions. The nutrient solution was renewed every 3-4 days (unless indicated otherwise). Five-week-old plants ( 3 weeks on plates and 2 weeks on hydroponics) were further used for experiments. They were exposed to chosen $\mathrm{Zn}$ (as $\mathrm{ZnSO}_{4}$ ) concentrations added to quarter-strength Knop's medium. Details are given in the subsections 2.3 and 2.9 below. At the end of each experiment, the plant samples were collected always at the same time of the day (between 10-12 AM). The quarter-strength Knop's medium (containing $0.5 \mu \mathrm{M} \mathrm{Zn}$ ) was used as a reference (control) medium in parallel to applied $\mathrm{Zn}$ treatments.

Plants were cultivated in a growth chamber at temperature $23 / 16^{\circ} \mathrm{C}$ day/night, $40-50 \%$ humidity, $16 \mathrm{~h}$ photoperiod, and quantum flux density [photosynthetically active radiation (PAR)] $250 \mathrm{mmol} \mathrm{m}^{-2} \mathrm{~s}^{-1}$, fluorescent Flora tubes.

\section{Database Search for Putative Tobacco Metal Transport Family Members}

The goal was to identify potential tobacco metal transporters involved in the accumulation of $\mathrm{Zn}$ in leaves. There are two sources of tobacco sequences to be used for gene mining. First, the complete genomic tobacco sequence has recently been made available to the public in GenBank with accession code AWOK00000000 (Sierro et al., 2013, 2014). Second, there is the NCBI database which provides already annotated genes from a range of species including tobacco. In tobacco, only several metal transporters have been already identified, cloned and characterized, some more were annotated and their sequences could be found in the NCBI database. Thus, NCBI database likely does not contain all tobacco genes. Therefore, the search for putative tobacco $\mathrm{Zn}$ transporters was performed with the use of both AWOK and NCBI databases. Tobacco metal transporters were identified based on homology to the previously annotated sequences of Arabidopsis thaliana genes belonging to the following major metal transport families: (i) ZIPs: ZRT, IRT-like proteins; (ii) NRAMPs: natural resistance-associated macrophage proteins; (iii) MTP: metal tolerance proteins; (iv) MRP/ABCC: multidrug resistance proteins.

The genome of Nicotiana tabacum, Basma Xanthi has been downloaded from http://www.ncbi.nlm.nih.gov/Traces/wgs/?\& $\mathrm{val}=\mathrm{AWOK} 01(\mathrm{BX})$, and a search for tobacco sequences homologous to sequences of metal transporters gene from A. thaliana was performed. For this we used program BLASTn (NCBI Resource Coordinators, 2016) which was run using an amino acid sequence from Arabidopsis against the Basma Xanthi genome. We retained alignments with $e$-value not exceeding $1 e-05$. Next we used AAT package (Huang et al., 1997) for analyzing and annotating large genomic sequences containing introns. The predicted exons were further filtered in order to avoid spurious predictions (minimal length at least 10 amino acids, plus a threshold on confidence levels for both boundaries that were returned by AAT package).

In parallel, the NCBI database was used for BLASTn searches of Nicotiana sequences with homology to the already annotated A. thaliana sequences of metal transporters. FGENESH and FGENESH+ tools (Softberry, Mount Kisco, NY, United States ${ }^{1}$ ) were used to identify the untranslated regions (UTRs), exons, and introns within the scaffold containing sequences of chosen tobacco genes, and to predict putative proteins encoded by these genes. Protein sequence alignments were performed using ClustalW and the phylogenetic trees were constructed with MEGA7.0 software (Tamura et al., 2013) using the maximum likelihood method with 1000 bootstrap replicates. The prediction of membrane-spanning regions and orientation was performed using Phobius software (Käll et al., 2004).

\section{Identification of Metal Transport Genes Differentially Regulated in Leaves by Exposure to Zn Excess}

The 5-week old tobacco plants (obtained as described in the section "Plant Material and Growth Conditions") were grown for the next 4 days in the control medium, then they were exposed to $200 \mu \mathrm{M} Z \mathrm{Zn}$ (added to the quarter-strength Knop's medium) for up to 3 days. Quarter-strength Knop's medium (contains $0.5 \mu \mathrm{M} \mathrm{Zn}$ ) served as a reference condition. On the 1st, $2 \mathrm{nd}$, and $3 \mathrm{rd}$ day of the $\mathrm{Zn}$ treatment blades from the $2 \mathrm{nd}$

\footnotetext{
${ }^{1}$ http://www.softberry.com
} 
leaf (counting from the base of a plant) were collected. Leaves were cut out from each plant, petioles and the major midribs were excised, and the fragments of the blades were immediately frozen in liquid nitrogen. Three independent biological replicate experiments were performed. For each repetition, the leaf blade fragments were collected from a total of 40 plants.

Quantitative Real-Time PCR (RT-qPCR) was used to determine which putative metal transport genes out of those identified by bioinformatics analysis (see section "Database Search for Putative Tobacco Metal Transport Family Members") are differentially regulated in the leaf blades by $200 \mu \mathrm{M} \mathrm{Zn}$ (as compared with the control conditions). Specific primers were designed for the sequences of identified metal transport genes from the ZIP, NRAMP, MTP, and MRP/ABCC families identified in the tobacco genome databases (Supplementary Table S1).

\section{Cloning of NtZIP1-Like and Bioinformatic Analysis}

The whole sequence of ZIP1-like was determined by $5^{\prime}$ - and $3^{\prime}$ rapid amplification of cDNA ends (RACE) using SMARTer RACE 5'/3' Kit (Clontech Laboratories, Inc. and A Takara Bio Company, Mountain View, CA, United States) according to the manufacturer's manual. Briefly, the partial sequence of ZIP1-like (previously identified in the tobacco genome database at AWOK01S302253.1) was used to design genespecific primers (GSPs) for the $5^{\prime}$ - and $3^{\prime}$-RACE reactions [2253GSP1-1-UPM (5') 2253-GSP2-1-UPM (3')] (Supplementary Table S1). Amplification of the $5^{\prime}$ - and $3^{\prime}$-end was performed in $50 \mu \mathrm{l}$ reactions with the use of the Phusion HF polymerase (Thermo Scientific). The PCR product of an expected size was electrophoresed on an $1 \%$ agarose/EtBr gel and excised DNA fragment was cleaned with the Macherey-Nagel PCR clean-up Gel extraction (Germany, VWR MANB740609.50) according to the manufacturer's instruction. It was cloned into the pRACE vector (provided with the SMARTer RACE kit) and subsequently the reaction mixture was used to transform Escherichia coli Stellar Competent Cells. The plasmids were isolated from individual colonies, and the presence of the expected insert was confirmed by PCR screening (starters M13/For and M13/Rev), then by sequencing (Genomed, Poland). Nucleic and amino acid sequence alignments between obtained sequence and sequence predicted by Fgenesh program was performed using ClustalW.

The full length NtZIP1-like cDNA sequence was amplified by PCR (Supplementary Table S1), subcloned to $\mathrm{pENTR}^{\mathrm{TM}} / \mathrm{D}$ TOPO $^{\circledR}$ and used for E. coli One Shot ${ }^{\mathrm{TM}}$ TOP10 (Invitrogen) transformation. The insert was sequenced to confirm the correct sequence. The sequence of the NtZIP1-like cDNA was deposited to the NCBI database (2015) under the accession number XM_016652513.

\section{RNA Extraction}

Total RNA was extracted from samples stored in $-80^{\circ} \mathrm{C}$ with the use of an RNeasy Plant Kit (Syngen, \#SY341010) according to the manufacturer's recommendations, followed by DNase I digestion (Qiagen, \#79254). The samples of RNA were quantified at $260 \mathrm{~nm}$ using a Nanodrop spectrophotometer ND 100
(Nanodrop, Wilmington, DE, United States). RNA concentration and purity was determined before and after DNA digestion using a NanoDrop spectrophotometer ND-1000 (Nanodrop, Wilmington, DE, United States) and the 260/280-nm ratio showed expected values between 1.8 and 2.0. The RNA integrity of samples was also confirmed by electrophoresis in agarose gel.

\section{Quantitative Real-Time PCR}

The cDNA used as a template for the RT-qPCR reaction was synthesized using RevertAid ${ }^{\mathrm{TM}}$ First Strand cDNA Synthesis Kits (Fermentas) in a $20 \mu \mathrm{l}$ reaction volume containing $1-3 \mu \mathrm{g}$ of aRNA and oligo d(T)18 primers following the manufacturer's protocol. The RT-qPCR reaction was performed according to procedures described in Kendziorek et al. (2016) with minor modifications. It was performed in a Roche mastercycler (LightCycler ${ }^{\circledR} 480$ System, Roche) using Light Cycler480 SYBR Green (Master 0488735001) according to the manufacturer's recommendations. The primers (Supplementary Table S1) were designed using IDT OligoAnalyzer $3.1^{2}$ and OligoCalc: Oligonucleotide Properties Calculator ${ }^{3}$. The tobacco NtPP2A (protein phosphatase 2A; AJ007496) gene was used as the reference gene/internal control and was amplified in parallel with the target gene allowing gene expression normalization and providing quantification. Their stability in the plant samples collected for expression analysis was measured and shown in Supplementary Figure S1. Expression analysis was performed with at least three independent biological replicates. For each sample, reactions were set up in triplicate and means were calculated. Quantification of the relative transcript levels was performed using the comparative $\underline{\mathrm{dCt}}$ (threshold cycle) method. Validation experiments were performed to test the efficiency of the target amplification and the efficiency of the reference amplification. The general quality assessment of the qPCR results was based on the amplification and melting curve profile of the samples in relation to the assay controls (non-template controls).

\section{Functional Analysis of NtZIP1-Like in Saccharomyces cerevisiae Strains}

The full cDNA of NtZIP1-like was amplified using Phusion polymerase with the primers introducing XbaI and BamHI restriction sites for amplification (Supplementary Table S1). Obtained sequence was restriction ligated into the pUG35 yeast expression vector (kindly provided by Dr. M. Migocka, The University of Wrocław). The open reading frame (ORF) of NtZIP1-like was inserted in frame C-terminal to the ORF of EGFP (construct pUG35-NtZIP1-like-EGFP) and with the STOP codon (construct pUG35-NtZIP1-like), and fused with the methionine-repressible MET25 promoter (Kurat et al., 2006; Petschnigg et al., 2009). The same cloning strategy has been used to fuse the EGFP coding region to the $\mathrm{N}$-terminal end of the NtZIP1-like in the pUG36 vector (construct pUG36-EGFP-NtZIP1-like). The resulting constructs and empty vectors were transformed to

\footnotetext{
${ }^{2} \mathrm{http} / / /$ eu.idtdna.com/calc/analyzer

${ }^{3} \mathrm{http}: / /$ www.basic.northwestern.edu/biotools/oligocalc.html
} 
yeasts using the lithium acetate method (Gietz and Schiestl, 2007).

The yeast strains used in this study were DY1457 (MATa, ade1 can1 his3 leu2 trp1 ura3), the mutant ZHY3 - $\Delta$ zrt1/zrt2 (DY1457 + zrt1::LEU2, zrt2::HIS3) defective in high and low affinity zinc uptake, and $\Delta$ fet3fet 4 (MATa trp1 ura3 Dfet3::LEU2 Dfet4::HIS3), defective in high and low affinity iron uptake system. Yeast strains were grown on liquid synthetic complete medium (SC-URA-MET/Glu) of the following composition: yeast nitrogen base supplemented with amino acids (without uracil and methionine), 2\% (w/v) glucose, $\mathrm{pH} 5.3$ (containing $0.2 \mathrm{mM} \mathrm{Zn}$ ) overnight at $30^{\circ} \mathrm{C}$ with shaking. On the next day the $\mathrm{OD}_{600}$ was measured, adjusted to $\mathrm{OD}_{600}$ of approximately 0.2 and yeasts were grown for another $2-5 \mathrm{~h}$. The $\mathrm{OD}_{600}$ was measured again, adjusted to $\mathrm{OD}=0.3$, series of dilutions were made $(1.0,0.1,0.01,0.001$, and 0.0001$)$ and $3 \mu \mathrm{l}$ aliquots of each yeast culture were spotted onto plates containing (SC-URAMET/Glu) medium solidified with $2 \%$ (w/v) agar supplemented with components depending on needs.

To determine whether $\mathrm{Zn}$ is a substrate for the NtZIP1like, the $\Delta z r t 1 / z r t 2$ yeast strain with the expression of pUG35, pUG35-NtZIP1-like, pUG35-NtZIP1-like-EGFP, pUG36 or pUG36-EGFP-NtZIP1-like and WT (DY1457) with the expression of pUG35 or pUG36 (empty vector) were grown on liquid SC-URA-MET/Glu medium (containing $0.2 \mathrm{mM} \mathrm{Zn}$ ) and spotted onto the agar-solidified SC-URA-MET/Glu medium containing series of EGTA (ethylene glycol-bis( $\beta$-aminoethyl ether)- $\mathrm{N}, \mathrm{N}, \mathrm{N}^{\prime}, \mathrm{N}^{\prime}$-tetraacetic acid) concentrations: 2.5, 5.0. 7.5, and $10.0 \mathrm{mM}$. Yeast growth was monitored for the next 5 days.

To examine if Cd is a substrate for the NtZIP1-like, yeast WT (DY1457) was transformed with the pUG35, pUG35-ZIP1-like and pUG35-ZIP1-like-EGFP, and spotted onto the agar-solidified SC-URA -MET/Glu medium containing range of $\mathrm{Cd}$ (as $\mathrm{CdCl}_{2}$ ) concentrations $(5,10,20,50$, and $75 \mu \mathrm{M})$. The sensitivity to cadmium was monitored.

To determine whether $\mathrm{Fe}$ is a substrate for the NtZIP1like, complementation of the growth defect of $\Delta$ fet3fet4 mutant line by expression of NtZIP1-like (the same constructs as above were used for expression) was tested on plates containing agar-solidified SC-URA-MET/Glu control medium. Moreover, modification of the sensitivity to high $\mathrm{Fe}$ due to expression of NtZIP1-like was examined on medium supplemented with 50 or $100 \mu \mathrm{M} \mathrm{FeCl}_{3}$.

\section{Subcellular Localization of NtZIP1-Like Protein}

The entire cDNA sequence of the ORF of NtZIP1-like were obtained using Phusion polymerase and primers introducing CACC at the $5^{\prime}$ end of the amplicon (underlined): forward $5^{\prime}$ CACCATGAATAACCACAATGTCCAAGT $3^{\prime}$ and reverse $5^{\prime}$-AGCCCATTTAGCCATCACAGA - $3^{\prime}$. The CACC overhand in the forward primer is required for directional cloning in the $\mathrm{pENTR} / \mathrm{D} \mathrm{TOPO}^{\circledR}$ vector (add provider). Following amplification, the cDNA was ligated into a Gateway entry vector pENTR/D-TOPO (Invitrogen). Fusion proteins with GFP were produced by the recombination (LR reaction) of entry vectors pENTR/D-TOPO-NtZIP1-like with destination vector pMDC43
(N-terminal GFP) (Curtis and Grossniklaus, 2003) using the Gateway system (Invitrogen).

Resulting construct pMDC43-GFP-ZIP1-like was sequenced (Genomed, Poland), then used for determination of the subcellular localization of the NtZIP1-like in tobacco cells. The pMDC43-GFP-ZIP1-like fusion protein was transiently expressed in tobacco leaves as described by Siemianowski et al. (2013). Leaves of 6-week-old WT tobacco grown on control medium were infiltrated with Agrobacterium tumefaciens carrying the pMDC43-GFP-ZIP1-like construct. Three days from the infiltration, leaves were analyzed using a Nikon A1 confocal laser scanning microscope (Melville, NY, United States). GFP signals were detected by excitation with the $488 \mathrm{~nm}$ line of the argon laser and emission was recorded between 500 and $560 \mathrm{~nm}$. To confirm plasma membrane localization of NtZIP1-like, cell walls at the plasma membrane border of examined tobacco epidermal cells were visualized by staining with the $50 \mu \mathrm{M}$ water solution propidum iodide $(20 \mathrm{~min})$, a membrane-impermeant red fluorescent dye (Suh et al., 2007; McFarlane et al., 2010). Imaging was detected by $543 \mathrm{~nm}$ excitation and $617 \mathrm{~nm}$ emission. In parallel, chlorophyll autofluorescence was monitored using a $\mathrm{HeNe}(543 \mathrm{~nm})$ laser for excitation.

\section{Hydroponic Experiments}

Developmental Regulation of NtZIP1-Like Expression

To study the organ-specific expression of NtZIP1-like which depends on a developmental stage of the vegetative phase of growth the 3-week old tobacco plants were transferred from the agar plates to the control liquid medium (see section "Plant Material and Growth Conditions") and cultivated for up to 6 weeks. For the first 3 weeks on hydroponics the nutrient solution was changed every 3-4 days (plants were grown in 2$\mathrm{L}$ plastic pots, five plants per pot). Next they were transferred to $1.2-\mathrm{L}$ pots (two plants per pot) for the consecutive 3 weeks, and the medium was changed every 2 nd day. The plant samples were collected at three stages of vegetative development: (Stage 1) small seedlings (3 weeks at the plates and 1 week on hydroponics); (Stage 2) young plants with rosette leaves (3 weeks on plates and 3 weeks on hydroponics); (Stage 3) adult plants with formed stem (3 weeks on plates and 6 weeks on hydroponics). At the Stage 1 and Stage 2 all leaf blades and all roots were collected separately. At the Stage 3 the following organs were collected: (i) from the aerial part of each plant - (a) two young leaves counting from the top (length of the blade of the smallest one was $0.5 \mathrm{~cm}$ ); (b) two oldest leaves (counting from the base); (c) stem $-3 \mathrm{~cm}$ of the middle part; (ii) rootstwo segments of the roots which grew out directly from the hypocotyl (adventitious roots were not included into analysis): (a) apical segment: $3-4 \mathrm{~cm}$ measured from the tip of the root; (b) basal segment: 3-4 cm measured from the base of the root. Plant samples were immediately frozen in the liquid nitrogen and stored in $-80^{\circ} \mathrm{C}$ until expression analysis. Three independent biological replicate experiments were performed. For each repetition samples were collected from a total of 30 plants (for Stage 1), 15 plants (for Stage 2) and 10 plants (for Stage 3). 
Regulation of the Expression of NtZIP1-Like by Zinc To determine if the expression of NtZIP1-like depends on $\mathrm{Zn}$ availability, the 5-week old plants (see section "Plant material and growth conditions") were grown for the next 4 days in the control medium, then they were subjected to the following treatments: (i) to $\mathrm{Zn}$ deficit ( $\mathrm{Zn}$ was omitted from the medium) for 4 days; (ii) to $\mathrm{Zn}$ deficit for 4 days followed by re-supply with control conditions for 2 days; (iii) to $\mathrm{Zn}$ excess (50 $\mu \mathrm{M} \mathrm{Zn}$ present in the control medium) for 1 day; (iv) control medium in parallel to all treatments. At the end of each experiment plant material was collected, frozen in liquid nitrogen, and stored in $-80^{\circ} \mathrm{C}$ for expression analysis. The following organs were collected: (i) the blades of the 2 nd and 3rd leaf (counting from the base) without petioles and the major midribs; (ii) two sectors of the roots which grew out directly from the hypocotyl (adventitious roots were not included into analysis): (a) 3-4 cm of the apical region; (b) $3-4 \mathrm{~cm}$ of the basal region. Three independent biological replicate experiments were performed. Samples were collected from a total of 10 plants for each repetition.

\section{Statistical Analysis}

All presented data are from one experiment that is representative of three to four independent replicate experiments. Statistical significance was evaluated at the 0.05 probability level using Student's $t$-test.

\section{RESULTS}

\section{Bioinformatic Analysis of Transporter Families in Tobacco}

Arabidopsis thaliana cDNAs from major metal transport families were used as the query sequences to identify genes encoding $\mathrm{Zn}$ transporters in tobacco. By screening the tobacco genome scaffolds, sequences of tobacco genes that significantly matched with the query cDNAs (query coverage $>80 \%$ ) were selected. The following protein families from $A$. thaliana were included in the search: (i) ZIPs: ZRT, IRT-like proteins; (ii) NRAMPs: natural resistance-associated macrophage proteins; (iii) MTPs: metal tolerance proteins; (iv) MRP/ABCC: multidrug resistance proteins. For each gene from $A$. thaliana used as a query, several tobacco homologous sequences were identified on different scaffolds. These sequences were screened for exon orientation, start and end positions, and confidence scores for the boundaries (Supplementary Table S2). Further the selected tobacco scaffolds were screened to identify full putative genomic sequences of NtZIP, NtNRAMP , NtMTP, and NtMRP (ABCC) genes, including transcription start sites, exons, introns, and polyadenylation sites using the FGENESH tool (Salamov and Solovyev, 2000), whereas Phobius system based on a hidden Markov model (HMM) approach, was applied to predict membrane topology of NtZIP1-like protein. The list of genomic sequences comprises twenty-one newly identified tobacco putative metal transporters. Their names were given according to the NCBI terminology of the genes from $A$. thaliana, which were used as a query (Supplementary Figure S2). Identified sequences (Supplementary Figure S2) were used to design primer pairs (Supplementary
Table S1) for determination of their transcript level in the leaf blades of tobacco plants exposed to high $\mathrm{Zn}$.

\section{Response of Genes from the ZIP, NRAMP, MTP, and MRP/ABCC Families in Tobacco Leaves to High Zn}

To determine which of the identified metal transporters could be potentially involved in the regulation of $\mathrm{Zn}$ in tobacco leaves, their expression in the blades of plants grown in the presence of $200 \mu \mathrm{M} \mathrm{Zn}$ for up to 3 days was compared to the control conditions (Figure 1). From the ZIP family, three genes were identified with a several-fold difference in the transcript level between the $\mathrm{Zn}$-exposed plants relative to those grown at the control medium. The most significant change was noted for NtZIP1-like and NtZIP4 (downregulation) and NtZIP11 (upregulation). Within the NtNRAMPs elevated expression was detected for a putative transporter NtNRAMP3-like. Moreover, modified expression was noted for three isoforms of NtMTP2. Out of identified six putative $M R P / A B C C$ transporters which were subjected to analysis, the expression of three of them (NtMRP10-like and at lower level NtMRP5-like and NtMRP14like) were modified by high $\mathrm{Zn}$.

\section{Phylogenetic Relationship of NtZIP1-Like from Tobacco}

In this study, the focus was on finding genes potentially involved in the accumulation of $\mathrm{Zn}$ in tobacco leaves, which respond to high Zn. The ZIP family proteins are considered as major Zn uptake transporters (Ricachenevsky et al., 2015). Based on downregulation of NtZIP1-like by high $\mathrm{Zn}$ in leaves (Figure 1), the assumption was made that it plays a role in $\mathrm{Zn}$ influx into the cytosol. Therefore, the NtZIP1-like was chosen for cloning and characterization.

The ORF of the new tobacco ZIP family member - NtZIP1like, consists of 1104 bp (Table 1) with 3 exons (Figure 2), and according to the prediction made by the program Fgenesh encodes 367 amino acids. To define the evolutionary relationship between ZIP1-like and the ZIP1 proteins from other organisms, as well as the other ZIPs, a phylogenetic tree was constructed (Figure 3). It included ZIP proteins from three species of tobacco (NtmZIP1-like, NsZIP1-like and NaZIP1-like), from A. thaliana, $M$. truncatula, and $V$. vinifera. It shows that NtZIP1-like is most closely related to ZIP1 proteins from other organisms including tobacco (NtmZIP1-like, NsZIP1-like and NaZIP1-like), Medicago truncatula (MtZIP1), Vitis vinifera (VvZIP1), and A. thaliana (AtZIP1). Within all ZIP1 sequences under comparison, NtZIP1 (Sano et al., 2012) formed a distinct clade with MtZIP3 and MtZIP4 from M. truncatula. The alignment of protein sequences defined at the phylogenetic tree as the closest homologs showed that the structure of NtZIP1-like is in agreement with the structure of other ZIP family members (Grotz and Guerinot, 2006). It contains eight transmembrane domains (TMs), a longer N-terminal region, a very short $\mathrm{C}$ tail, and a cytosolic variable region between TM domains III and IV (Figure 4). Histidine residues in the TMs II, IV, and V are highly conserved throughout the entire ZIP family. Our sequence analysis shows 


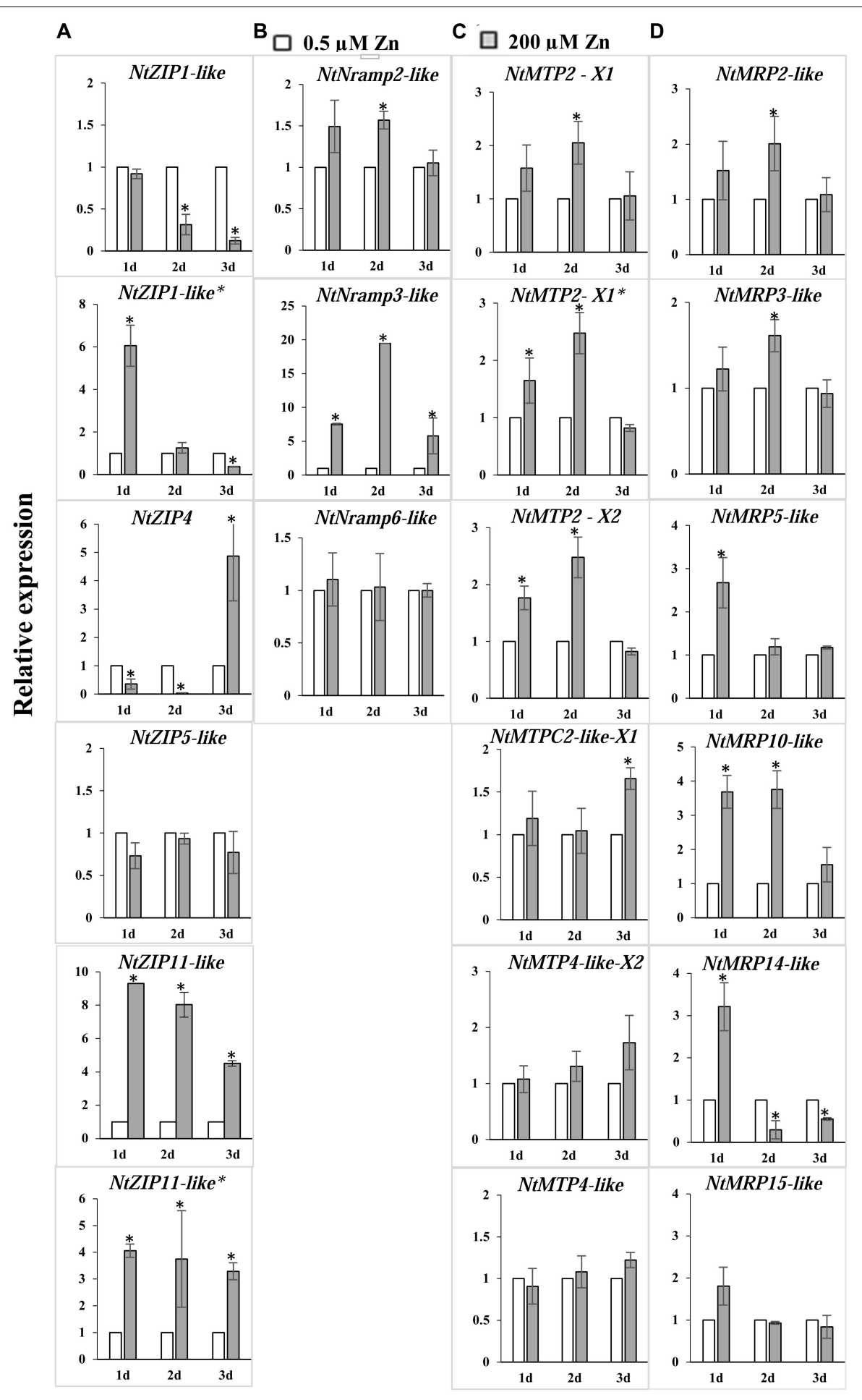

Exposure to Zn (days)

FIGURE 1 | Expression of metal transport genes in the leaves of Nicotiana tabacum plants grown under control conditions (white bars) and at $200 \mu \mathrm{M} Z \mathrm{Zn}$ (gray bars). RT-qPCR was used to determine transcript levels. Genes from four metal transport families were included in the analysis: NtZIPS (A), NtNRAMPS (B), NtMTPS (C), and NtMRPs/NtABCCs (D). The 5.5-week-old plants were grown for up to 3 days in the presence of $200 \mu \mathrm{M} Z \mathrm{n}$ added to the control medium (0.5 $\mu \mathrm{M} Z \mathrm{Zn})$, and in parallel in the control medium. The average transcript levels are presented for three technical replicates. Gene expression was normalized to the PP2A level. Expression under control conditions was set to 1 as the frame of reference within each experiment. Values correspond to means $\pm \operatorname{SD}(n=3)$; those significantly different from the control (Student's $t$-test) are indicated by an asterisk $(P \leq 0.05)$. 
TABLE 1 | Sequence identity between the NtZIP1-like and ZIP1 predicted proteins from selected species (sequences were chosen based on phylogenetic tree given in Figure 3).

\begin{tabular}{|c|c|c|c|c|c|}
\hline Name of gene & Accession no. & No. of amino acid & Identity of NtZIP1-like (\%) (aa) & Length of gene (bp) & Identity of NtZIP1-like (\%) (bp) \\
\hline NtZIP1-like & XM_016652513 & 367 & - & 1104 & - \\
\hline AtZIP1 & At3g12750 & 355 & 56 & 1068 & 58 \\
\hline NtmZIP1-like & XP_009608181 & 367 & 100 & 1104 & 100 \\
\hline NaZIP1-like & XM_019401009 & 370 & 94 & 1113 & 96 \\
\hline NsZIP1-like & XM_009773722 & 370 & 95 & 1113 & 97 \\
\hline MtZIP1 & AAR08412 & 358 & 59 & 1077 & 67 \\
\hline VVZIP1 & XP_002264603 & 360 & 57 & 1083 & 66 \\
\hline NtZIP1 & NM_001325745 & 339 & 54 & 1020 & 62 \\
\hline
\end{tabular}

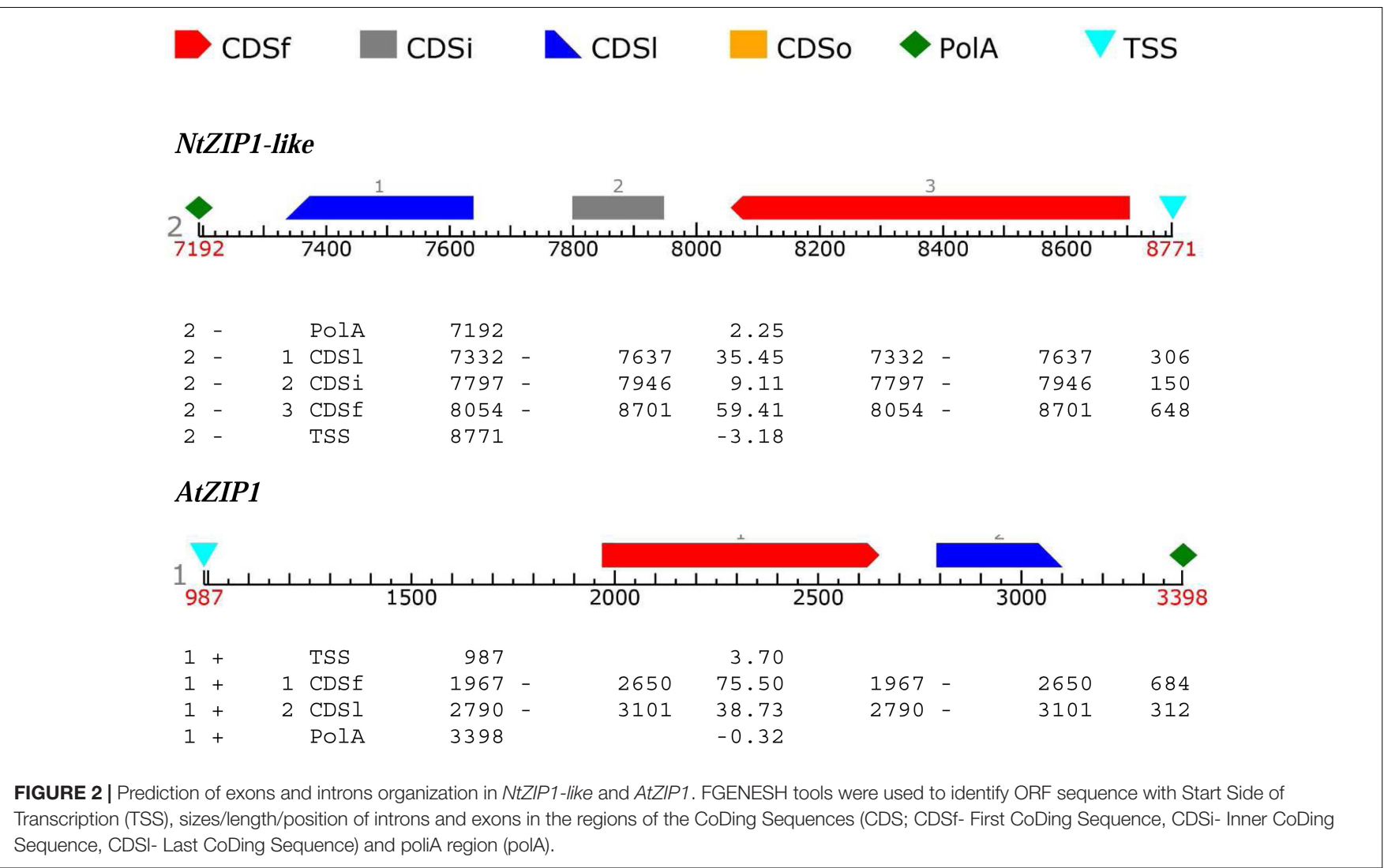

that NtZIP1-like exhibits high amino acid sequence similarity with AtZIP1 and other known ZIP family members within these three mentioned TM domains (Figure 4). Among them, amino acid sequence conservation within the signature region in the fourth TM domain was found. It contains consensus sequences (including a fully conserved histidine residue). On the other hand, a potential metal-binding motif containing multiple histidine residues present in the variable region between TM III and IV, differs between examined proteins primarily in the number of his residues and their localization. In this region, eight histidine residues were found in NtZIP1-like compared to nine present for example in AtZIP1, and only three in NtZIP1 (Figure 4). The NtZIP1 protein (Sano et al., 2012) formed also a separate clade containing AtZIP3 and MtZIP3, MtZIP4 and AtZIP5.
The NtZIP1-like shares 56 and 54\% identity at the amino acid level with AtZIP1 and NtZIP1, respectively, whereas 58 and 62\% at the nucleotide level. The highest homology was found between the NtZIP1-like and other three tested tobacco ZIP1 proteins such as NtnZIP1-like (100\%), NaZIP1-like (94 and 96\%) and NsZIP1-like (95 and 97\%, respectively (Table 1).

\section{NtZIP1-Like Localizes to the Plasma Membrane}

To gain insight into the functioning of NtZIP1-like, its subcellular localization was determined by transient expression of the NtZIP1-like protein fused to the $\mathrm{N}$ terminus of green fluorescent protein (GFP) under the control of the cauliflower mosaic virus (CaMV) 35S promoter in tobacco leaves. 


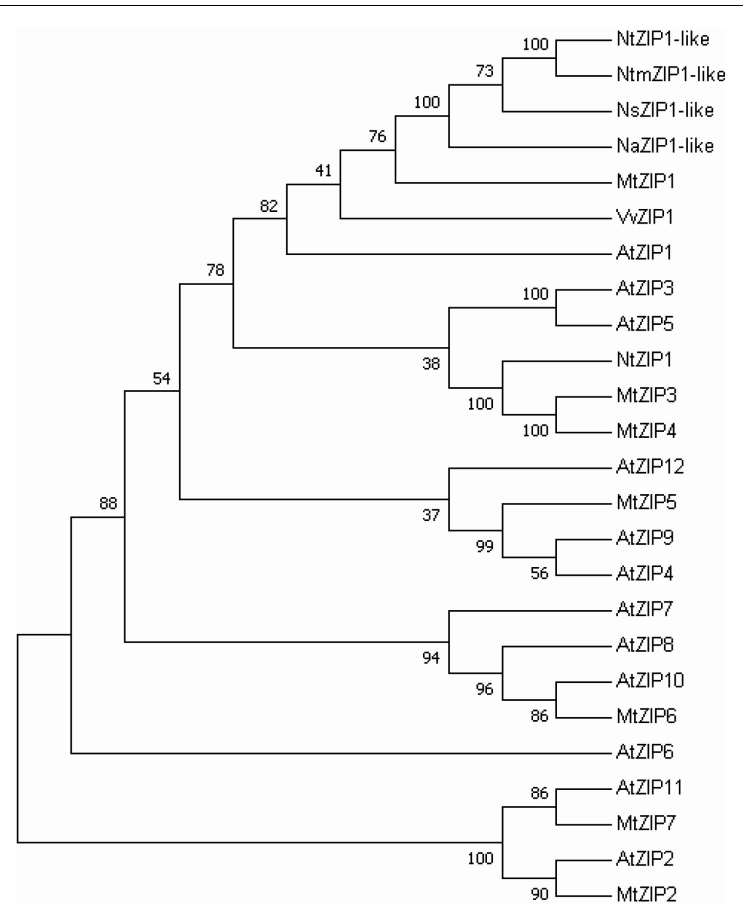

FIGURE 3 | Phylogenetic analysis of ZIP1 transporters from selected species. The unrooted tree was constructed based on amino acid sequences identified in the Aramemnon (Arabidopsis thaliana) and NCBI database (Nicotiana species, Medicago truncatula, Vitis vinifera), using the MEGA 7.0 software. The lengths of branches are proportional to the degree of divergence. Numbers in the figure represent bootstrap values (1000 replicates). The accession numbers are as follows: Arabidopsis thaliana, AtZIP1 At3g12750.1, AtZIP2 - At5g59520.1, AtZIP3 - At2g32270.1, AtZIP4 At1g10970.1, AtZIP5 - At1g05300.1, AtZIP6 - At2g30080.1, AtZIP7 At2g04032.1, AtZIP8 - At5g45105.1, AtZIP9 - At4g33020.1, AtZIP10 At1g31260.1, AtZIP11 - At1g55910.1, AtZIP12 - At5g62160.1; Nicotiana attenuata, NaZIP1-like XP_019256554; Nicotiana tabacum, NtZIP1-like XP_016507999, NtZIP1- NP_001312674; Nicotiana sylvestris: NsZIP1-like XP_009772024; Nicotiana tomentosiformis, NtomZIP1-like XP_009608181; Medicago truncatula: MtZIP1 - AAR08412.1, MtZIP2 - AAG09635, MtZIP3 AY339055, MtZIP4 - AY339056, MtZIP5 - AY339057, MtZIP6 - AY339058, MtZIP7 - AY339059; Vitis vinifera, VvZIP1 - XP_002264603.2.

Three days after the infiltration of the leaves with Agrobacterium expressing pMDC43-GFP-ZIP1-like, the GFP signal (green fluorescence) was detected in tobacco epidermal cells along the cell walls indicating localization of NtZIP1-like protein at the plasma membrane (Figure 5). Cell walls were stained with propidium iodide and the green fluorescence (Figure 5A) coincided with the red signal, derived from propidium iodide (Figures 5B,C). The co-localization of the GFP-derived signal and propidium iodide staining of the cell walls indicates localization of GFP-fused NtZIP1-like protein at the plasma membrane (Pighin et al., 2004; Lee et al., 2010; Siemianowski et al., 2013). Moreover, at higher magnification the signal from the cell wall (red) and from the GFP-labeled plasma membrane (green) were separated (indicated by arrows; Figures 5E-G). Altogether, results support the conclusion that NtZIP1-like is a plasma membrane protein.

\section{Yeast Complementation Supports a Role for NtZIP1-Like as a Zn Transporter}

Yeast functional complementation was used to determine the capacity of NtZIP1-like to transport Zn. The yeast zrt1zrt2 double mutant (ZHY3) defective in high and low affinity $\mathrm{Zn}$ uptake was used (Eide, 2003). The expression of fulllength cDNA of NtZIP1-like gene fused with the eGFP at its C-terminal end (construct pUG35EGFP-NtZIP1-like-EGFP), as well as at its N-terminal end (construct pUG36-EGFP-NtZIP1like) did not complement the growth defect of the $\Delta z r t 1 z r t 2$ yeast mutant (Figure 6A). In contrast, the expression of the construct pUG35-NtZIP1-like (with the STOP codon) fully restored growth under Zn-limited conditions (Figure 6A). These result indicates that NtZIP1-like is a plasma membrane protein mediating $\mathrm{Zn}$ uptake. The lack of rescue by constructs containing EGFP both at the C- and N-terminal end suggests that the presence of the eGFP protein makes the NtZIP1-like protein dysfunctional.

Some ZIP proteins mediate transport of $\mathrm{Cd}$ (Ramesh et al., 2003; Nakanishi et al., 2006; Stephens et al., 2011). To determine if NtZIP1-like is a Cd uptake protein, the wild-type yeast line DY1457 was transformed with pUG35-NtZIP1-like (with the STOP codon), and pUG35-NtZIP1-like-EGFP. If the NtZIP1-like is involved in Cd influx, the yeast transformants should be more sensitive to this metal. As shown in Figure 6B the growth of the wild-type transformed with the empty vector or with both tested constructs was limited by a range of $\mathrm{Cd}$ present in the medium to the same extent indicating no $\mathrm{Cd}$ transport capacity by NtZIP1-like.

Finally, to study the capacity of the NtZIP1-like to transport $\mathrm{Fe}$, a yeast mutant $\Delta$ fet3fet 4 defective in both high- and low affinity Fe uptake systems was transformed with the NtZIP1-like cDNA to examine if it complements the defect in Fe transport. As shown in Figure 6C, expression of NtZIP1-like in the $\Delta$ fet3fet4 did not restore the growth of mutants at control conditions, and it did not modify the sensitivity of yeast to Fe excess. To conclude, the results indicate that the NtZIP1-like does not transport Fe.

\section{Developmental Regulation of NtZIP1-Like}

Our study showed that NtZIP1-like is expressed both in the roots, leaves and stems, but the level depends on the developmental stage (Figure 7). The transcript level in the leaves was very low in young 4-week old plants compared to a 6-fold increase in 6week old tobacco. In the adult 9-week old plants its expression in young leaves was 3-times higher than in the old ones. NtZIP1-like was expressed at a moderate level in stems. In the roots of young 4-week old plants the transcript level was very low, and a 6-fold increase was detected in 6-week old tobacco. It remained at that level in adult 9-week old plants and did not differ in the apical and basal part of the root.

\section{Expression of NtZIP1-Like Is Zn Regulated}

It has been shown that $\mathrm{Zn}$ is a substrate for NtZIP1-like. To know more about the possible physiological role of NtZIP1-like 


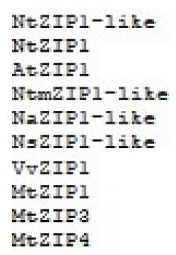

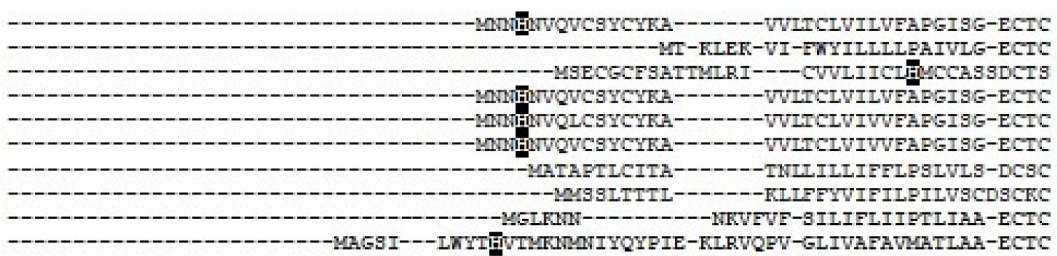

I

II

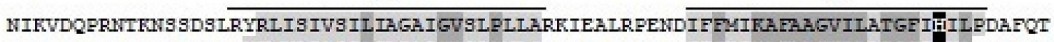

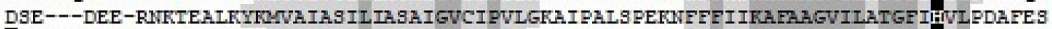

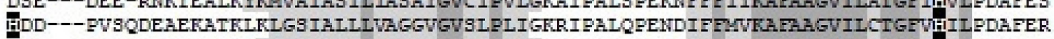
WIKVDQPRNTFWS SDSLRYRLI I IVS IL IAGA I GVSLPLLARKIEALRFENDI FFMTKARAAGVILATGEIHIILFDAFQT

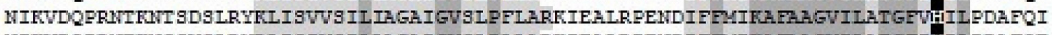

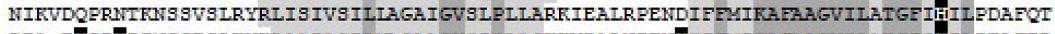

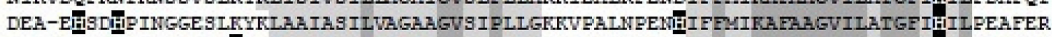

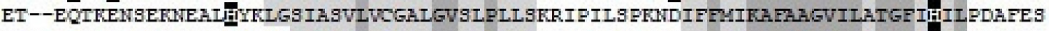

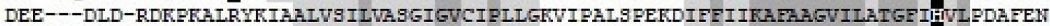

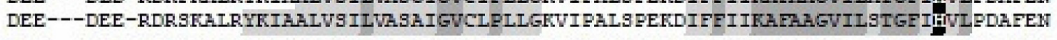

\section{III}

HDM

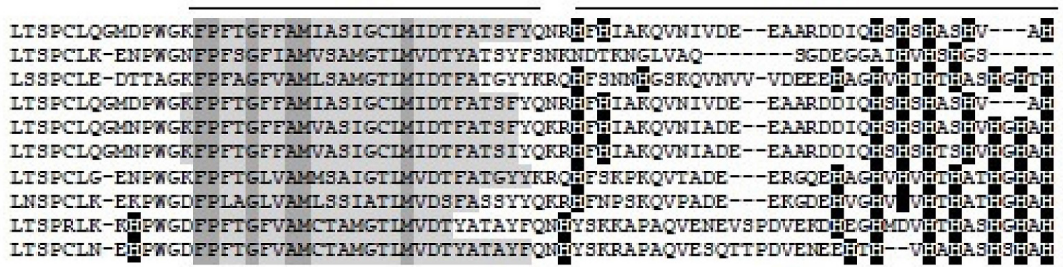
IV

$\mathrm{V}$

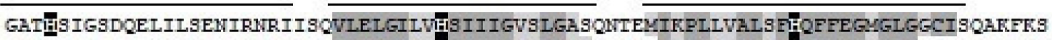

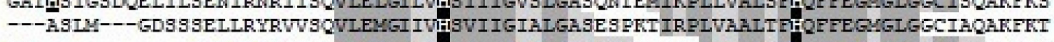

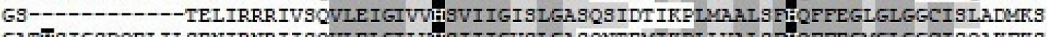

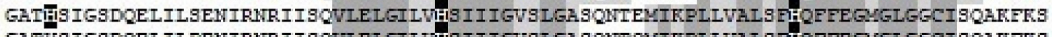

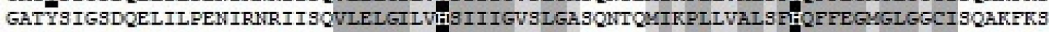

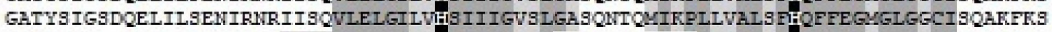
GSASPSD---EESLSDLIRRRIVBOVLELGIVWHSVI I GVSIGASQREETIFRLLAALSEHCEFEGL GLGGCISOARFRF GSATSSQ---DSISPEL IRORI I SCVLELGIVVHSVI I GISLGTAQSIDTIKFLLVALSEHOFFE GMGLGGCIBQARFES GSATSSQ---DSISPELIRORI I SVVLELGIVVHSVI I GI SLGTAQSIDTIFPLIVALSEHCFFEGMGLGGCISQARFES

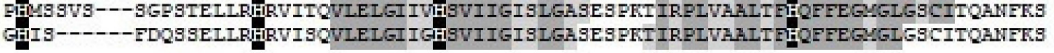
VI VII

TSTAIMSVLFSLTTPAGIGIGIGISR--VWMAHSSISLIVEGILNSASSGILIMALVDILASDERNPRMGMVRLICGA

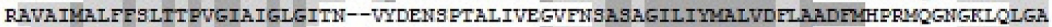

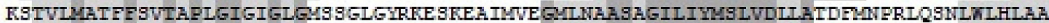

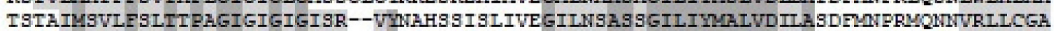

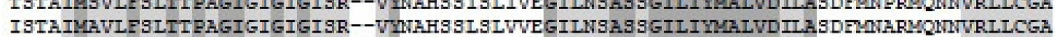

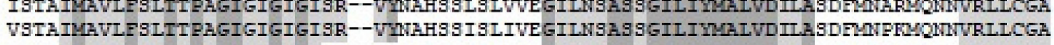

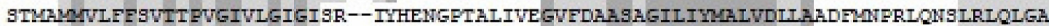
R.STAIMATFESLTTPIGIAIGAGVS--VYKDNSPTSLIVEGVFNSASAGILIMALVDLIAADFNSPRMONDFEIOIGA

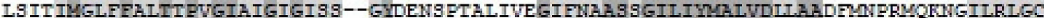

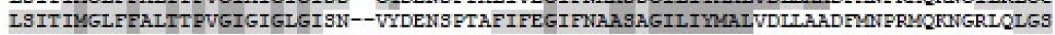

\section{VIII}

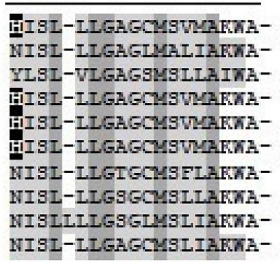

FIGURE 4 | Amino acid alignment of predicted ZIP proteins from different species. Sequences were aligned using ClustalW. The prediction of membrane-spanning regions was performed using Phobius software and indicated as lines above the sequences, and numbered I-VIII, respectively. The identical amino acids are indicated with dark gray. HDM indicates the histidine rich domain within the variable cytosolic region. Dashes indicate gaps.

in tobacco, its expression was analyzed in the roots, leaves and stems of plants exposed to $\mathrm{Zn}$ excess (50 $\mu \mathrm{M}$ for 1 day), and to $\mathrm{Zn}$-deficiency (no Zn for 4 days) subsequently followed by a replete conditions (4-day Zn deficit followed by 2 days of control conditions). In agreement with downregulation in the leaf blades by $200 \mu \mathrm{M} \mathrm{Zn}$ (Figure 1), downregulation by 1-day exposure to $50 \mu \mathrm{M} \mathrm{Zn}$ was detected in leaves, and in the roots (both in the apical and basal segment) (Figure 8). Interestingly, its expression was highly upregulated by Zn-deficiency in the leaves and in the basal segment of the roots. No response to low $\mathrm{Zn}$ in the medium 
A

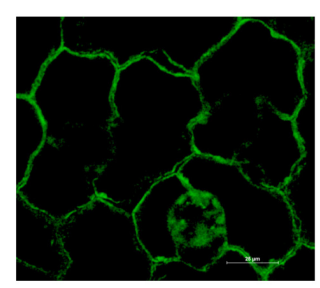

E

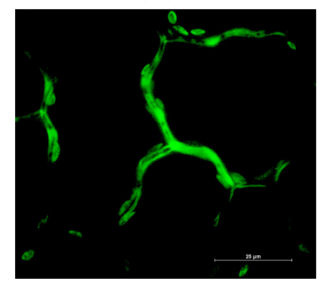

B

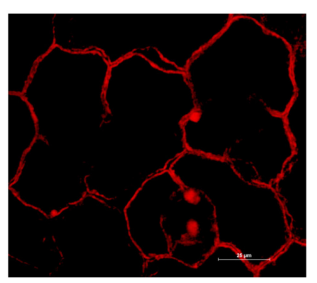

$\mathbf{F}$

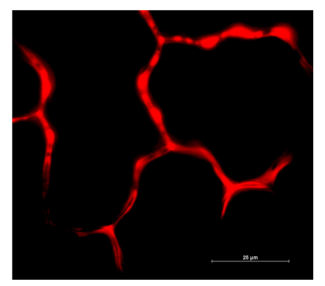

C

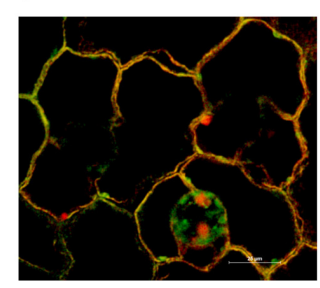

G

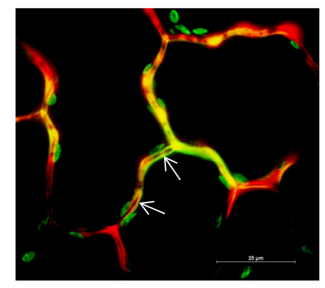

D

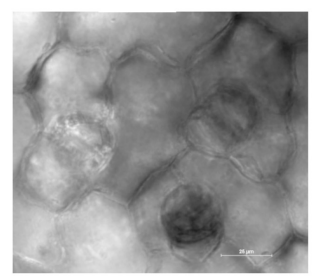

H

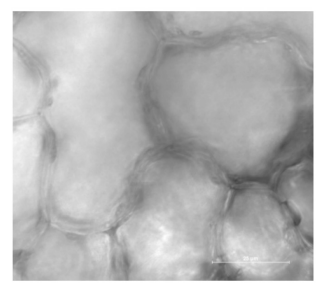

FIGURE 5 | Plasma membrane localization of the NtZIP1-like-GFP fusion protein transiently expressed in tobacco leaf epidermis. Confocal images of two areas of NtZIP1-like-GFP expressing epidermal cells (A-D; E-H). Sections were labeled with propidium iodide. GFP fluorescence concentrated to the plasma membrane (A,E); propidium iodide staining red of the same cells follows their contours (B,F); overlapped GFP and propidium iodide signal (C,G); bright field (D,H). Locally, signal from the cell wall (stained red) clearly visible between adjacent GFP-labeled plasma membranes (arrows).

was noted in the apical part of the root considered as primarily responsible for Zn uptake (Figure 8).

\section{DISCUSSION}

Although tobacco, as a plant with a high capacity to accumulate large amount of metals (including $\mathrm{Zn}$ and $\mathrm{Cd}$ ) in leaves, is used for phytoremediation of metal contaminated soil (Herzig et al., 2003, 2014; Lugon-Moulin et al., 2004; Dguimi et al., 2009; Vangronsveld et al., 2009), metal transporters involved in uptake and storage of metals in leaf tissues remain unknown. Here, based on bioinformatics searches for tobacco metal transporter sequences (Supplementary Figure S2 and Supplementary Table S2), and subsequent analysis of the regulation of the candidate genes by $\mathrm{Zn}$ excess $(200 \mu \mathrm{M} \mathrm{Zn})$ in leaves, ten genes (out of twenty-one tested) with significantly modified expression were identified (Figure 1). They represent putative metal transport genes that likely contribute to the storage of $\mathrm{Zn}$ excess in tobacco leaves, and include transporters involved in sequestration, redistribution and uptake of metals.

In sequestration of $\mathrm{Zn}$ in tobacco leaves exposed to $200 \mu \mathrm{M} \mathrm{Zn}$ three isoforms of NtMTP2 may play a role. Elevated expression of two isoforms of NtMTP2-X1 and NtMTP2-X2 (Figure 1C) suggests a likely involvement in loading of $\mathrm{Zn}$ into vacuoles, which are the major storage compartments within cells. The MTP2 proteins are not fully characterized so far in plants. It is known that the MTP2 belongs to the Group 1 of MTP vacuolar $\mathrm{Zn}$ transporters. Phylogenetic analysis showed that MTP1, MTP2, and MTP3 originate from a common MTP1/2/3 ancestors (Gustin et al., 2011).

The concentration of a metal in vacuoles depends not only on efficient loading, but also on the rate of mobilizing vacuolar pool back to the cytosol, which, among others, is under control of
NRAMP proteins. In tobacco leaves expression of NtNRAMP3like was significantly induced by high Zn supply (Figure 1B). Oomen et al. (2009) showed that TcNRAMP3/4 (and to a lesser extent AtNRAMP3/4) expression is regulated by $\mathrm{Zn}$ supply (lowefficient-excess), though the pattern of the regulation has not been fully established. However, until now $\mathrm{Zn}$ has not been shown to be a substrate for NRAMP3. The AtNRAMP3 from A. thaliana and TcNRAMP3 from T. caerulescens mediate efflux of Fe, Cd, and $\mathrm{Mn}$ from vacuoles to the cytoplasm (Thomine et al., 2003; Oomen et al., 2009). Ability to transport not only Fe, Mn, Cd but also Zn was shown for AtNRAMP4 and TcNRAMP4 only (Oomen et al., 2009). Thus, future studies will show whether the NtNRAMP3-like is localized to the tonoplast (like AtNRAMP3 or TcNRAMP3) or to the plasma membrane (like e.g., OsNRAMP3; Yamaji et al., 2013), what the substrates are, and what its role in the accumulation of high amounts of $\mathrm{Zn}$ in tobacco leaves.

The next identified new putative metal transporters regulated upon high $\mathrm{Zn}$ concentration in tobacco leaves are from the MRP/ABCC family. The major changes were found for the NtMRP10-like and NtMRP14-like, whereas to a lesser extent for NtMRP2-like, NtMRP3-like and NtMRP5-like (Figure 1D). The MRP/ABCC proteins carry various xenobiotics including metal complexes. Until now, there are only a few studies on plants indicating involvement of $\mathrm{MRP} / \mathrm{ABCC}$ proteins in the transport of metals as conjugates to various substrates (Klein et al., 2006). Heterologous expression of AtMRP7 in tobacco has suggested a role in $\mathrm{Cd}$ transport into the root vacuoles (Wojas et al., 2009). AtABCC1 and AtABCC2 were shown to be targeted to the tonoplast and mediated the vacuolar sequestration of phytochelatin (PC) complexes with $\mathrm{Cd}$ (II) and $\mathrm{Hg}$ (II) (Park et al., 2012). The MRP/ABCC genes have been shown to be regulated by metals. For example, the expression of AtMRP3 is induced by $\mathrm{Cd}, \mathrm{Ni}, \mathrm{As}, \mathrm{Co}$, and $\mathrm{Pb}$, but not $\mathrm{Zn}$ or Fe (Bovet et al., 2003; Zientara et al., 2009). Upregulation by Cd was also 


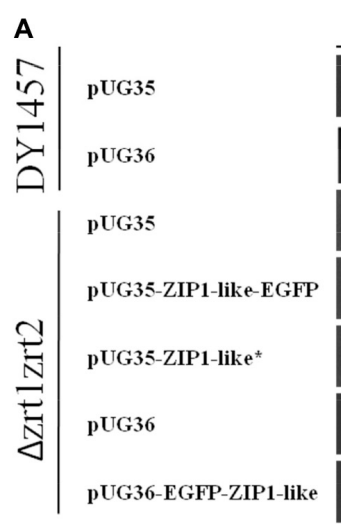

B $\mid \begin{aligned} & \text { pUG35 } \\ & \text { pUG35-ZIP1-like-EGFP } \\ & \text { pUG35-ZIP1-like* } \\ & \text { pUG36 } \\ & \text { pUG36-EGFP-ZIP1-like }\end{aligned}$

C

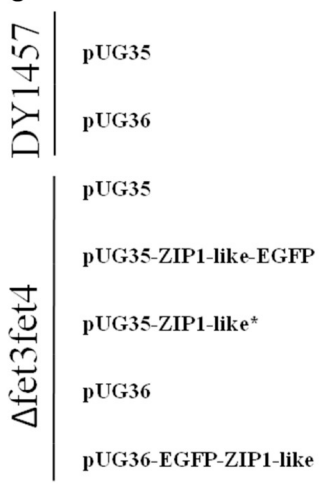
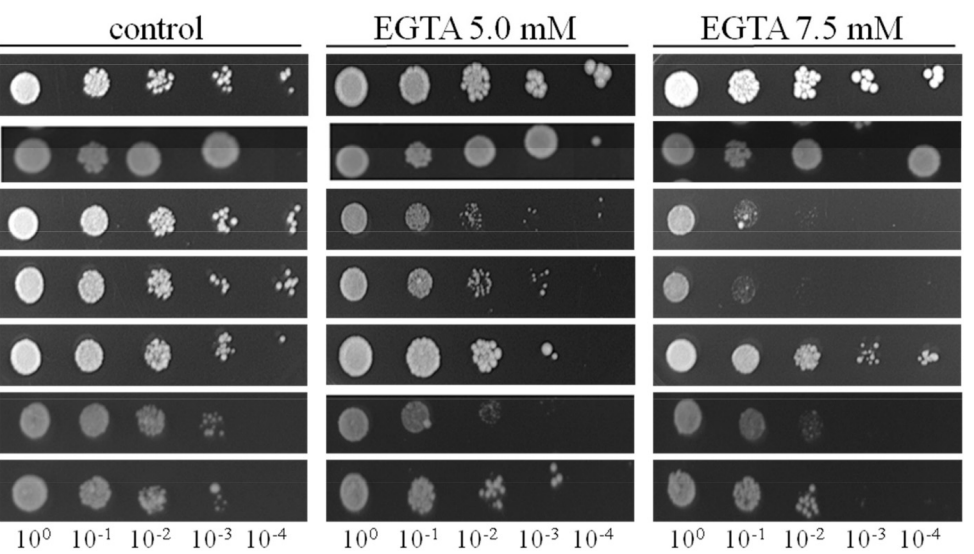

control

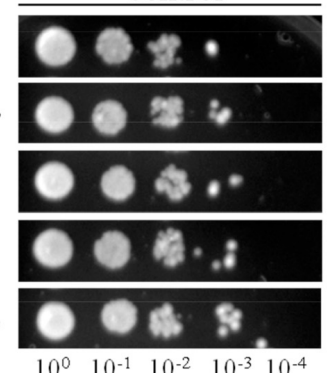

$\begin{array}{lllll}10^{0} & 10^{-1} & 10^{-2} & 10^{-3} & 10^{-4}\end{array}$
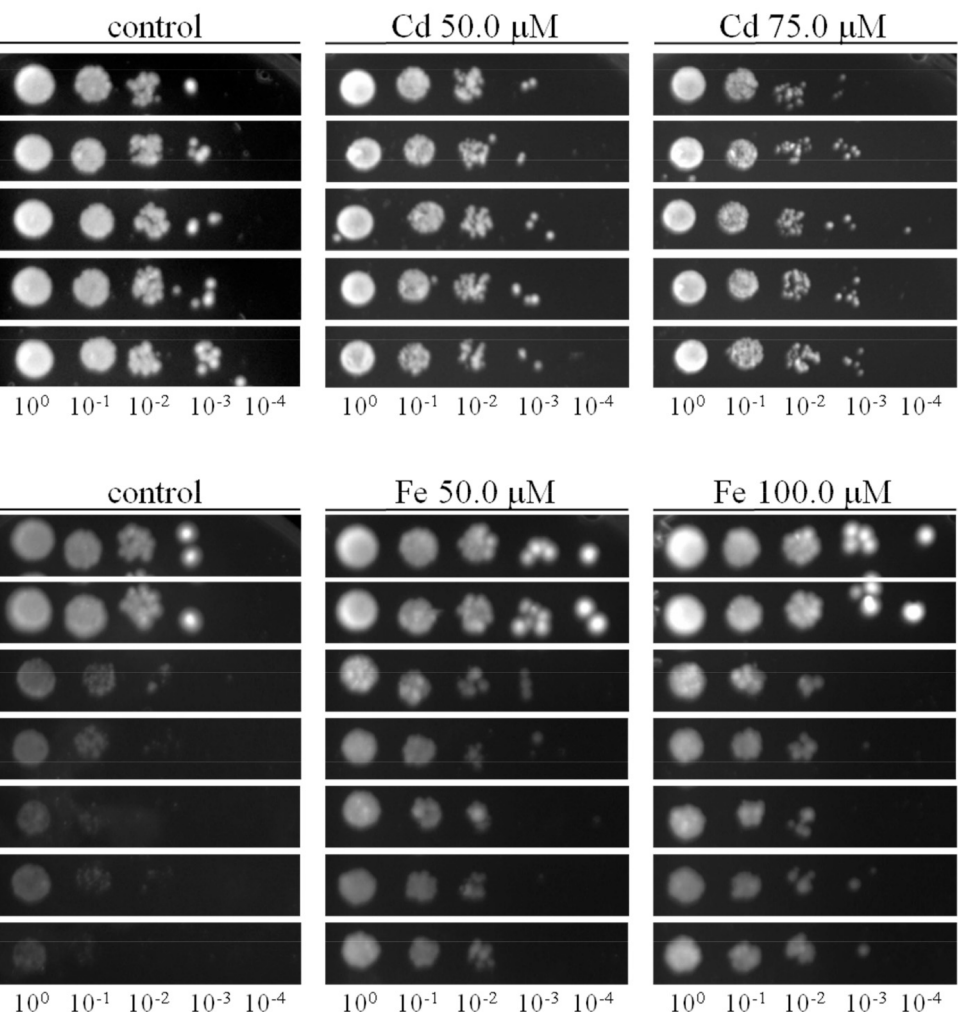

FIGURE 6 | Complementation by NtZIP1-like cDNA of yeast mutants defective in metal uptake on selective media. Yeast cells: DY1457, $\Delta$ zrt1zrt2 (defective in Zn uptake), $\Delta$ fet3fet4 (defective in Fe uptake) were transformed with empty vectors pUG35/36 as a control, or with vectors carrying tobacco gene NtZIP1-like with $(*$ ) or without a stop codon. Yeast cultures were adjusted to an OD600 of 0.2 , and $3 \mu$ of serial dilutions (from left to right in each panel) was spotted on SC-URA-MET medium supplemented with EGTA (A), $\mathrm{CdCl}_{2}$ (B) or $\mathrm{FeCl}_{3}$ (C) or $0.2 \mu \mathrm{M} \mathrm{Zn}$ (control). The plates were incubated for 3-6 d at $30^{\circ} \mathrm{C}$. The images are representative of three independent experiments.

confirmed for AtMRP6 (Gaillard et al., 2008) and AtMRP7 (Bovet et al., 2003), and by high $\mathrm{Zn}$ for TcMRP10 in the roots and shoots of $\mathrm{Zn}$ hyperaccumulator T. caerulescens (Hassinen et al., 2007). Identification in tobacco leaves of such $\mathrm{Zn}$-responsive $\mathrm{MRP} / \mathrm{ABCC}$ genes is important for future study on the regulation of $\mathrm{Zn}$ homeostasis upon treatment with high $\mathrm{Zn}$.

The emphasis in this study was to shed more light on the regulation of $\mathrm{Zn}$ acquisition by cells in the leaves. The ZIP proteins constitute a major $\mathrm{Zn}$ uptake system (Sinclair and Krämer, 2012). Here, the NtZIP1-like was cloned and characterized to better understand its function in tobacco.

NtZIP1-like contains an ORF of 1104 bp, encoding a predicted protein of 367 amino acids (Table 1). Phylogenetic analysis of the ZIP family proteins shows that the NtZIP1-like forms a distinct clade with other ZIP1 proteins from three tobacco species (NatmZIP1-like, NsZIP1-like, and NaZIP1-like), A. thaliana, $M$. truncatula and $V$. vinifera (Figure 3). Sequence comparisons (Figure 4) showed that the deduced NtZIP1-like protein shares 


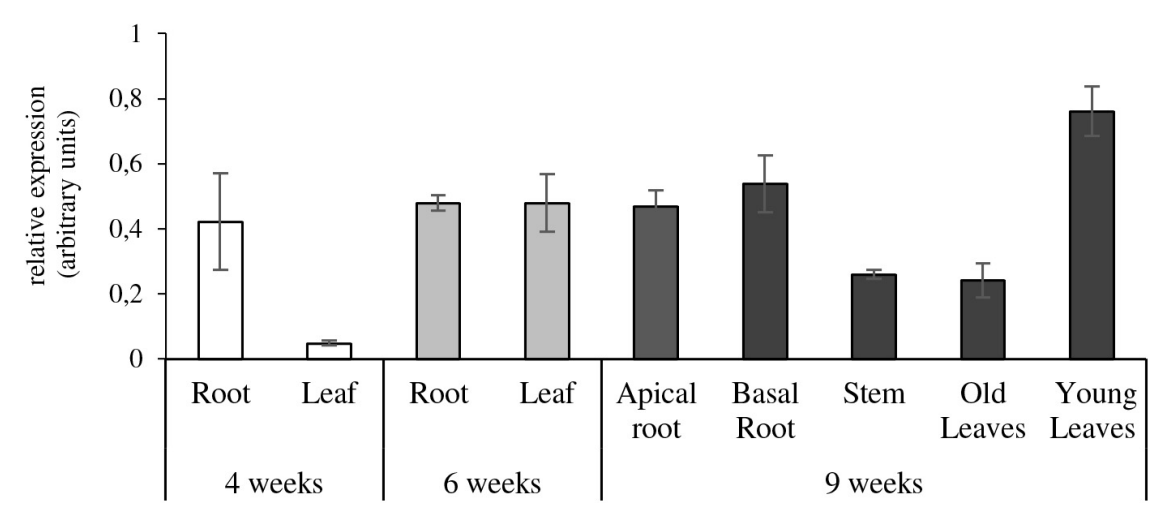

FIGURE 7 | Organ- and developmental-regulation expression of NtZIP1-like in N. tabacum. Analysis was performed by RT-qPCR. Plants were grown at control conditions. Transcript levels were monitored in 4-week-old plants (whole roots and leaves); 6-week-old plants (whole roots and leaves), and 9-week-old plants (apical and basal segments of roots, stems, young leaves, old leaves). The level of NtZIP1-like transcript was normalized to PP2A expression level.

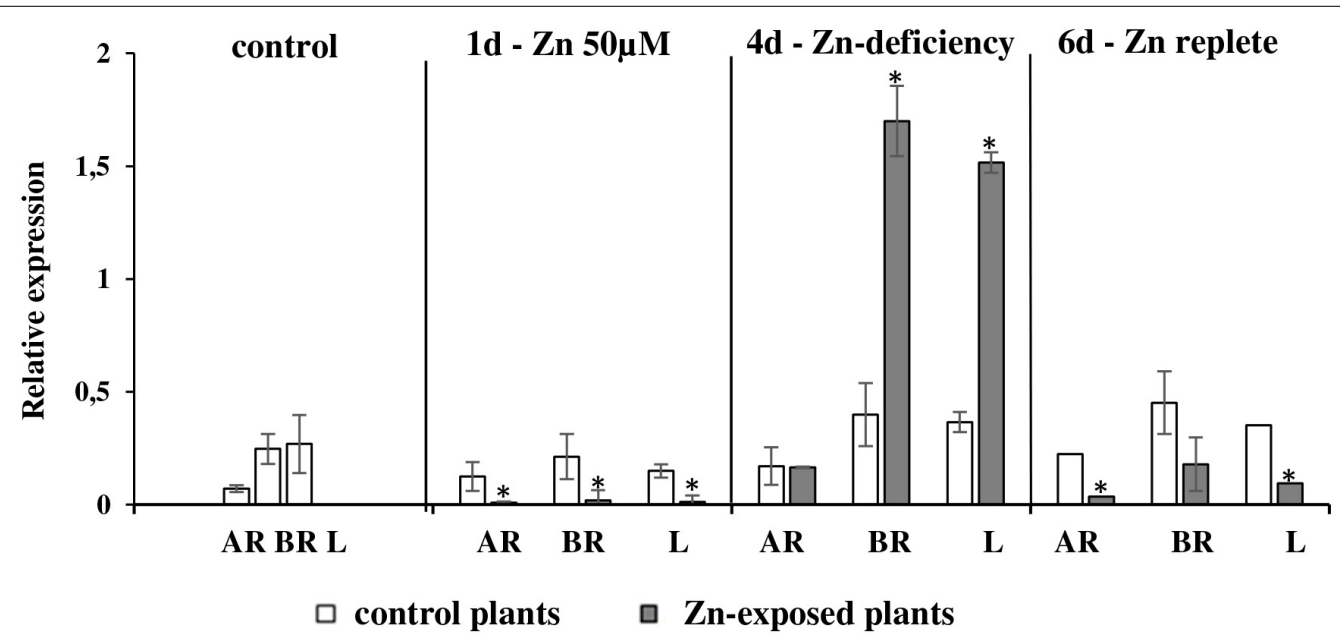

FIGURE 8 | Expression pattern of NtZIP1-like in N. tabacum under various Zn conditions. Plants were grown in standard nutrient solution (control) and then transferred into modified control media: supplemented with $50 \mu \mathrm{M}$ Zn for 1 day (1d); without Zn for 4 days (4d - Zn deficiency); plants grown at Zn-deficiency conditions for 4 days were transferred to the control medium for 2 days ( $6 \mathrm{~d}$ - Zn replete). RT-qPCR analyses was performed on cDNA prepared from leaves (L), apical part of roots (AR) and basal part of roots (BR) of $N$. tabacum. Gene expression was normalized to the $P P 2 A$ level. Values correspond to means \pm SD $(n=3)$; those significantly different are indicated by an asterisk $(P \leq 0.05)$.

all the basic characteristic features of members of the ZIP family of metal transporters. It has eight TM domains, a long N-terminal end, a very short $\mathrm{C}$ tail, and a cytoplasmic variable region between TM III and IV (Figure 4). The variable region contains a histidine rich domain (HRD) with the motif $(\mathrm{HX})_{\mathrm{n}}(n=2,3$, and 4$)$ which has been proposed as a metal binding site. The characteristic feature of ZIP proteins is the presence of a signature motif within the TM IV, and highly conserved histidine residues in TM domains II, IV, and V (Eide et al., 1996; Eng et al., 1998; Grotz et al., 1998; Guerinot, 2000; Rogers et al., 2000; Gaither and Eide, 2001). They all are present in the NtZIP1-like (Figure 4).

Analysis showed that two tobacco ZIP1 proteins - newly cloned NtZIP1-like and NtZIP1 (Sano et al., 2012), do not cluster together (Figure 3). They share 54\% identity at the amino acid level (Table 1). Comparison of NtZIP1-like and NtZIP1 amino acids sequences (Figure 4) showed that an important difference between them lies within a variable cytoplasmic HRD region between the TM III and IV. Although this region displays low sequence conservation among ZIP metal transporters, most of them contain the motif $(\mathrm{HX})_{\mathrm{n}}(n=2,3$, and 4$)$, which has been proposed as a metal binding site (Eide et al., 1996; Eng et al., 1998; Grotz et al., 1998). Only three (HX) repetitions were detected in NtZIP1, whereas eight in the newly cloned NtZIP1-like. To compare, other ZIP1 proteins contain eight or nine $(\mathrm{HX})$ repetitions. The exact function of the loop between TM III-IV is yet to be determined, however, a study by Nishida et al. (2008) on the TjZNT1 ZIP transporter from Thlaspi japonica showed that deletion of a part of the HRD region containing his residues localized closer to the TM IV (HRD, position 207-217 aa) abolished Zn transport ability. Hence a difference in the structure at the amino acid level might contribute to a different substrate specificity. NtZIP1 and 
NtZIP1-like do seem to have different substrate specificities. The expression of NtZIP1 in yeast significantly enhanced Fe accumulation suggesting Fe uptake activity (Sano et al., 2012). In contrast, the NtZIP1-like failed to alter the Fe-limited growth defect of fet3fet 4 yeast mutant indicating it may not transport Fe (Figure 6C). NtZIP1-like is also unlikely to mediate Cd uptake since its expression in WT yeast did not modify the sensitivity to Cd (Figure 6B). Functional complementation of the $z r t 1 z r t 2$ mutant, defective in $\mathrm{Zn}$ uptake supports its potential role as a $\mathrm{Zn}$ transporter (Figure 6A). NtZIP1-like localizes to the plasma membrane when transiently expressed in tobacco (Figure 5). Therefore, our results indicate that NtZIP1-like is a tobacco ZIP1 uptake protein for Zn, but not for $\mathrm{Cd}$ or Fe. In general, an ability of ZIP1 proteins to transport Fe was shown for PtZIP1 (Fu et al., 2017). More Fe transporters were identified among other ZIP proteins for example ZmZIP2-8, OsZIP5 and OsZIP8 (Li et al., 2013), MtZIP3, 5, 6 (López-Millán et al., 2004), PtZIP7 (Fu et al., 2017) and NtZIP1 (Sano et al., 2012).

Expression of the NtZIP1-like was detected in all plant organs, which suggests rather a universal role in maintaining $\mathrm{Zn}$ homeostasis (Figure 7). Its role seems to be more pronounced at later developmental stages. The transcript level is greater in older plants, especially in younger leaves (as compared with the older ones) suggesting a contribution to supplying cells in developing organs with $\mathrm{Zn}$. Analysis of the regulation of the NtZIP1-like expression by $\mathrm{Zn}$ availability showed upregulation by $\mathrm{Zn}$-deficiency in the roots and leaves (Figure 8), which was similar to AtZIP1 and OsZIP1 (Ramesh et al., 2003; Milner et al., 2013). Interestingly, in the roots upregulation of NtZIP1-like was limited to the basal segment of the root only, and was not detected in the apical part. It is known that the young, apical segment of the root is responsible for acquisition of nutrients, however, not much is known about the role of the older, basal region. Our studies clearly indicate that NtZIP1-like is a $\mathrm{Zn}$-deficiency inducible $\mathrm{Zn}$ uptake transporter in leaves and in roots (though in roots the induction takes place only in the basal part; Figure 8). Further research is needed to demonstrate the NtZIP1-like tissue-specific expression and regulation, as it is not clear if it is involved in $\mathrm{Zn}$ acquisition from the medium, or in internal uptake. Distinct regulation of ZIP genes in a different root sectors has been shown also in rice (Ishimaru et al., 2005). Expression of OsZIP4 was detected in the meristematic region of the $\mathrm{Zn}$-deficient roots. Similarly, AtZIP2p::GUS expression analysis revealed higher induction in the younger region of the roots grown under nutrient-replete conditions, as compared to a lower induction nearer the mature part at the root-shoot junction (Weber et al., 2004). In general, it is known that upregulation upon $\mathrm{Zn}$ deficiency conditions and downregulation in replete medium is ascribed to genes involved in the acquisition of micronutrients (Sinclair and Krämer, 2012), and these two features are characteristic for NtZIP1-like (Figure 8).

It is known that in the leaves of tobacco plants exposed to $\mathrm{Zn}$ excess, the metal is not distributed equally throughout the mesophyll cells. Instead, high concentrations were found in clusters of adjacent cells ( $\mathrm{Zn}$-accumulating cells) in contrast to its low level in neighboring non-accumulating ones (Siemianowski et al., 2013). Distinct expression patterns of $\mathrm{Zn}$ transport genes must underlie such different $\mathrm{Zn}$ uptake and accumulation capacity. Knowing this, we searched for genes differentially regulated in the leaves by high $\mathrm{Zn}$. The NtZIP1-like was identified initially as downregulated by $200 \mu \mathrm{M} \mathrm{Zn}$ (Figure 1), and confirmed later as downregulated by $50 \mu \mathrm{M} \mathrm{Zn} \mathrm{(Figure} \mathrm{8).} \mathrm{We}$ hypothesize that the downregulation observed in leaves upon $\mathrm{Zn}$ excess could be a part of the molecular mechanism occurring in the low $\mathrm{Zn}$-accumulating cells that prevents them from excessive uptake of $\mathrm{Zn}$. Further comparative studies on the regulation of NtZIP1-like expression in leaves at low and high $\mathrm{Zn}$ at the cellular and tissue level are necessary in the future to investigate this.

\section{CONCLUSION}

The bioinformatics analysis using information from the tobacco genome and the detailed expression study has led to the identification of ten new tobacco putative transporters involved in the regulation of $\mathrm{Zn}$ accumulation in tobacco leaves. They belong to different major families of metal transporters (ZIP, NRAMP, MTP, and MRP/ABCC), and undergo differential regulation in the leaves of tobacco plants exposed to $200 \mu \mathrm{M} \mathrm{Zn}$. The upregulation of NtZIP11-like, NtNRAMP3, three isoforms of NtMTP2, three MRP/ABCC genes such as NtMRP10-like, NtMRP5-like and NtMRP14like, and downregulation of NtZIP1-like and NtZIP4, indicate their contribution to a range of processes underlying uptake, sequestration and redistribution of metals in the cells and tissues. These data provide an important input for further research on metal homeostasis mechanisms in tobacco, the species used for phytoremediation of metal contaminated soil.

The detailed study on the newly cloned NtZIP1-like showed that the encoded protein is localized to the plasma membrane and mediates uptake of $\mathrm{Zn}$, but not $\mathrm{Fe}$ or $\mathrm{Cd}$. It is expressed in the roots and leaves - but the level of the transcript depends on the developmental stage. It is also regulated by the availability of $\mathrm{Zn}$, being highly up-regulated by $\mathrm{Zn}$-deficiency specifically in the leaves and in the basal part of the root but not in the apical zone. We have shown previously that tobacco mesophyll cells have a distinct capacity to store $\mathrm{Zn}$ in the "Zn-accumulating cells" which are next to non-accumulating ones in the leaf blade (Siemianowski et al., 2013). Our detailed studies on the NtZIP1-like suggest that it might be a candidate gene involved in the restriction of $\mathrm{Zn}$ uptake by the mesophyll cells with low capacity to accumulate $\mathrm{Zn}$.

\section{AUTHOR CONTRIBUTIONS}

AP carried out all experiments. KK was involved in yeast study, cloning and expression analysis. MK was involved in cloning, expression analysis and hydroponic experiments. 
$\mathrm{AB}$ contributed to expression analysis. $\mathrm{MP}$ was involved in bioinformatics analysis and hydroponic experiments. JT performed bioinformatics analysis. BP contributed to confocal analysis. LW supervised yeast complementation assays. DA designed the study concept, coordinated the research and supervised experiments, performed data analysis, and wrote the manuscript. All authors read and approved the final manuscript.

\section{FUNDING}

This work was financially supported by National Science Center, Poland (Grant HARMONIA No. NZ3/00527).

\section{REFERENCES}

Astudillo, C., Fernandez, A. C., Blair, M. W., and Cichy, K. A. (2013). The Phaseolus vulgaris ZIP gene family: identification, characterization, mapping, and gene expression. Front. Plant Sci. 4:286. doi: 10.3389/fpls.2013.00286

Barabasz, A., Klimecka, M., Kendziorek, M., Weremczuk, A., Ruszczyńska, A., Bulska, E., et al. (2016). The ratio of $\mathrm{Zn}$ to $\mathrm{Cd}$ supply as a determinant of metalhomeostasis gene expression in tobacco and its modulation by overexpressing the metal exporter AtHMA4. J. Exp. Bot. 67, 6201-6214. doi: 10.1093/jxb/ erw389

Barabasz, A., Wilkowska, A., Tracz, K., Ruszczyńska, A., Bulska, E., Mills, R. F., et al. (2013). Expression of HvHMA2 in tobacco modifies Zn-FeCd homeostasis. J. Plant Physiol. 170, 1176-1186. doi: 10.1016/j.jplph.2013. 03.018

Bashir, K., Ishimaru, Y., and Nishizawa, N. K. (2012). Molecular mechanisms of zinc uptake and translocation in rice. Plant Soil 361, 189-201. doi: 10.1007/ s11104-012-1240-5

Bovet, L., Eggman, T., Meylan-Bettex, M., Polier, J., Kammer, P., Marin, E., et al. (2003). Transcript levels of AtMRPs after cadmium treatment: induction of AtMRP3. Plant Cell Environ. 26, 371-381. doi: 10.1046/j.1365-3040.2003. 00968.x

Bovet, L., Feller, U., and Martinoia, E. (2005). Possible involvement of plant ABC transporters in cadmium detoxification: a cDNA sub-microarray approach. Environ. Int. 31, 263-267. doi: 10.1016/j.envint.2004.10.011

Cailliatte, R., Schikora, A., Briat, J. F., Mari, S., and Curie, C. (2010). Highaffinity manganese uptake by the metal transporter NRAMP1 is essential for Arabidopsis growth in low manganese conditions. Plant Cell 22, 904-917. doi: $10.1105 /$ tpc. 109.073023

Chen, W. R., Feng, Y., and Chao, Y. E. (2008). Genomic analysis and expression pattern of OsZIP1, OsZIP3, and OsZIP4 in two rice (Oryza sativa L.) genotypes with different zinc efficiency. Russ. J. Plant Physiol. 55, 400-409. doi: 10.1134/ S1021443708030175

Curtis, M. D., and Grossniklaus, U. (2003). A gateway cloning vector set for highthroughput functional analysis of genes in planta. Plant Physiol. 133, 462-469. doi: 10.1104/pp.103.027979

Desbrosses-Fonrouge, A. G., Voigt, K., Schroder, A., Arrivault, S., Thomine, S., and Kramer, U. (2005). Arabidopsis thaliana MTP1 is a Zn transporter in the vacuolar membrane which mediates $\mathrm{Zn}$ detoxification and drives leaf Zn accumulation. FEBS Lett. 579, 4165-4174. doi: 10.1016/j.febslet.2005. 06.046

Dguimi, H. M., Debouba, M., Ghorbel, M. H., and Gouia, H. (2009). Tissue-specific cadmium accumulation and its effects on nitrogen metabolism in tobacco (Nicotiana tabaccum, Bureley v. Fb9). C. R. Biol. 332, 58-68. doi: 10.1016/j.crvi. 2008.08.021

Dräger, D. B., Desbrosses-Fonrouge, A.-G., Krach, C., Chardonnens, A. N., Meyer, R. C., Saumitou-Laprade, P., et al. (2004). Two genes encoding Arabidopsis halleri MTP1 metal transport proteins co-segregate with zinc tolerance and account for high MTP1 transcript levels. Plant J. 39, 425-439. doi: 10.1111/j. 1365-313X.2004.02143.x

\section{ACKNOWLEDGMENTS}

We would like to thank Dr. Rafał Milanowski (Department of Molecular Phylogenetics and Evolution, Faculty of Biology, University of Warsaw Biological and Chemical Research Centre) for advice and comments on the construction of the phylogenetic tree.

\section{SUPPLEMENTARY MATERIAL}

The Supplementary Material for this article can be found online at: https://www.frontiersin.org/articles/10.3389/fpls.2018.00185/ full\#supplementary-material

Ducos, E., Fraysse, A. S., and Boutry, M. (2005). NtPDR3, an iron-deficiency inducible ABC transporter in Nicotiana tabacum. FEBS Lett. 579, 6791-6795. doi: 10.1016/j.febslet.2005.11.014

Eide, D., Broderius, M., Fett, J., and Guerinot, M. L. (1996). A novel ironregulated metal transporter from plants identified by functional expression in yeast. Proc. Natl. Acad. Sci. U.S.A. 93, 5624-5628. doi: 10.1073/pnas.93. 11.5624

Eide, D. J. (2003). Multiple regulatory mechanisms maintain zinc homeostasis in Saccharomyces cerevisiae. J. Nutr. 133, 1532S-1535S.

Eng, B. H., Guerinot, D., Eide, M. H., and Saier, J. (1998). Sequence analyses and phylogenetic characterization of the ZIP family of metal ion transport proteins. J. Membr. Biol. 166, 1-7. doi: 10.1007/s002329900442

Evens, N. P., Buchner, P., Williams, L. E., and Hawkesford, M. J. (2017). The role of ZIP transporters and group F bZIP transcription factors in the Zn-deficiency response of wheat (Triticum aestivum). Plant J. 92, 291-304. doi: $10.1111 /$ tpj.13655

Farthing, E. C., Menguer, P. K., Fett, J. P., and Williams, L. E. (2017). OsMTP11 is localised at the Golgi and contributes to Mn tolerance. Sci. Rep. 7:15258. doi: 10.1038/s41598-017-15324-6

Fu, X.-Z., Zhou, X., Xing, F., Ling, L.-L., Chun, C.-P., Cao, L., et al. (2017). Genome-wide identification, cloning and functional analysis of the Zinc/Ironregulated transporter-like protein (ZIP) gene family in Trifoliate Orange (Poncirus trifoliata L. Raf.). Front. Plant Sci. 8:588. doi: 10.3389/fpls.2017. 00588

Gaillard, S., Jacquet, H., Vavasseur, A., Leonhardt, N., and Forestier, C. (2008). AtMRP6/AtABCC6, an ATP-Binding Cassette transporter gene expressed during early steps of seedling development and up-regulated by cadmium in Arabidopsis thaliana. BMC Plant Biol. 8:22. doi: 10.1186/1471-2229-8-22

Gaither, L. A., and Eide, D. J. (2001). Eukaryotic zinc transporters and their regulation. Biometals 14, 251-270. doi: 10.1023/A:1012988914300

Gietz, D. R., and Schiestl, R. H. (2007). High-efficiency yeast transformation using the LiAc/SS carrier DNA/PEG method. Nat. Protoc. 3, 31-34. doi: 10.1038/ nprot.2007.13

Gisbert, C., Ros, R., DeHaro, A., Walker, D. J., Bernal, M. P., Serrano, R., et al. (2003). A plant genetically modified that accumulates $\mathrm{Pb}$ is especially promising for phytoremediation. Biochem. Biophys. Res. Commun. 303, 440-445. doi: 10.1016/S0006-291X(03)00349-8

Gorinova, N., Nedkovska, M., Todorovska, E., Simova-Stoilova, L., Stoyanova, Z., Georgieva, K., et al. (2007). Improved phytoaccumulation of cadmium by genetically modified tobacco plants (Nicotiana tabacum L.). Physiological and biochemical response of the transformants to cadmium toxicity. Environ. Pollut. 145, 161-170. doi: 10.1016/j.envpol.2006.03.025

Grotz, N., Fox, T., Connolly, E., Park, W., Guerinot, M. L., and Eide, D. (1998). Identification of a family of zinc transporter genes from Arabidopsis that respond to zinc deficiency. Proc. Natl. Acad. Sci. U.S.A. 95, 7220-7224. doi: 10.1073/pnas.95.12.7220

Grotz, N., and Guerinot, M. L. (2006). Molecular aspects of $\mathrm{Cu}, \mathrm{Fe}$ and $\mathrm{Zn}$ homeostasis in plants. Biochem. Biophys. Acta 1763, 595-608. doi: 10.1016/j. bbamcr.2006.05.014 
Guerinot, M. L. (2000). The ZIP family of metal transporters. Biochem. Biophys. Acta 1465, 190-198. doi: 10.1016/S0005-2736(00)00138-3

Gustin, J. L., Loureiro, M. E., Kim, D., Na, G., Tikhonova, M., and Salt, D. E. (2009). MTP1-dependent $Z n$ sequestration into shoot vacuoles suggests dual roles in $\mathrm{Zn}$ tolerance and accumulation in $\mathrm{Zn}$ hyperaccumulating plants. Plant J. 57, 1116-1127. doi: 10.1111/j.1365-313X.2008.03754.x

Gustin, J. L., Zanis, M. J., and Salt, D. E. (2011). Structure and evolution of the plant cation diffusion facilitator family of ion transporters. BMC Evol. Biol. 11:76. doi: 10.1186/1471-2148-11-76

Halimaa, P., Lin, Y.-F., Ahonen, V. H., Blande, D., Clemens, S., Gyenesci, A., et al. (2014). Gene expression differences between Noccaea caerulescens ecotypes help to identify candidate genes for metal phytoremediation. Environ. Sci. Technol. 48, 3344-3353. doi: 10.1021/es4042995

Hassinen, V. H., Tervahauta, A. I., Halimaa, P., Plessl, M., Peräniemi, S., Schat, H., et al. (2007). Isolation of $\mathrm{Zn}$-responsive genes from two accessionsof the hyperaccumulator plant Thlaspi caerulescens. Planta 225, 977-989. doi: 10.1007/s00425-006-0403-0

Hermand, V., Julio, E., deBorne, F. D., Punshon, T., Ricachenevsky, F. K., Bellec, A., et al. (2014). Inactivation of two newly identified tobacco heavy metal ATPases leads to reduced $\mathrm{Zn}$ and $\mathrm{Cd}$ accumulation in shoots and reduced pollen germination. Metallomics 6, 1427-1440. doi: 10.1039/c4mt $00071 \mathrm{~d}$

Herzig, R., Guadagnini, M., Rehnert, A., and Erismann, K. H. (2003). "Phytoextraction efficiency of in vitro-bred tobacco variants using a non-GMO approach," in Phytoremediation Inventory - COST Action, eds T. Vanek and J. P. Schwitzguébel (Prague: UOCHB AVCR), 73.

Herzig, R., Nehnevajova, E., Pfistner, C., Schwitzguebel, J.-P., Ricci, A., and Keller, C. (2014). Feasibility of labile Zn phytoextraction using enhanced tobacco and sunflower: results of five- and one-year field-scale experiments in Switzerland. Int. J. Phytoremediation 16, 735-754. doi: 10.1080/15226514.2013. 856846

Hodoshima, H., Enomoto, Y., Shoji, K., Shimada, H., Goto, F., and Yoshihara, T. (2007). Differential regulation of cadmium-inducible expression of irondeficiency-responsive genes in tobacco and barley. Physiol. Plant. 129, 622-634. doi: $10.1111 / j .1399-3054.2006 .00825 . x$

Huang, X., Adams, M. D., Zhou, H., and Kerlavage, A. R. (1997). A tool for analyzing and annotating genomic sequences. Genomics 1,37-45. doi: 10.1006/ geno.1997.4984

Hussain, D., Haydon, M. J., Wang, Y., Wong, E., Sherson, S. M., Young, J., et al. (2004). P-type ATPase heavy metal transporters with roles in essential zinc homeostasis in Arabidopsis. Plant Cell 16, 1327-1339. doi: 10.1105/tpc. 020487

Ishimaru, Y., Suzuki, M., Kobayashi, T., Takahashi, M., Nakanishi, H., Mori, S., et al. (2005). OsZIP4, a novel zinc-regulated zinc transporter in rice. J. Exp. Bot. 56, 3207-3214. doi: 10.1093/jxb/eri317

Käll, L., Krogh, A., and Sonnhammer, E. L. L. (2004). A combined transmembrane topology and signal peptide prediction method. J. Mol. Biol. 338, 1027-1036. doi: 10.1016/j.jmb.2004.03.016

Kendziorek, M., Klimecka, M., Barabasz, A., Borg, S., Rudzka, J., Szczęsny, P., et al. (2016). Engineering high $\mathrm{Zn}$ in tomato shoots through expression of AtHMA4 involves tissue-specific modification of endogenous genes. BMC Genomics 17:625. doi: 10.1186/s12864-016-2990-x

Klein, M., Burla, B., and Martinoia, E. (2006). The multidrug resistanceassociated protein (MRP/ABCC) subfamily of ATP-binding cassette transporters in plants. FEBS Lett. 580, 1112-1122. doi: 10.1016/j.febslet.2005. 11.056

Kobae, Y., Uemura, T., Sato, M. H., Ohnishi, M., Mimura, T., Nakagawa, T., et al. (2004). Zinc transporter of Arabidopsis thaliana AtMTP1 is localized to vacuolar membranes and implicated in zinc homeostasis. Plant Cell Physiol. 45, 1749-1758. doi: 10.1093/pcp/pci015

Korenkov, V., King, B., Hirschi, K., and Wagner, G. J. (2009). Root-selective expression of AtCAX4 and AtCAX2 results in reduced lamina cadmium in field-grown Nicotiana tabacum L. Plant Biotechnol. J. 7, 219-226. doi: 10.1111/ j.1467-7652.2008.00390.x

Kurat, C. F., Natter, K., Petschnigg, J., Wolinski, H., Scheuringer, K., Scholz, H., et al. (2006). Obese yeast: triglyceride lipolysis is functionally conserved from mammals to yeast. J. Biol. Chem. 281, 491-500. doi: 10.1074/jbc.M5084 14200
Lanquar, V., Lelièvre, F., Bolte, S., Hamès, C., Alcon, C., Neumann, D., et al. (2005). Mobilization of vacuolar iron by AtNRAMP3 and AtNRAMP4 is essential for seed germination on low iron. EMBO J. 24, 4041-4051. doi: 10.1038/sj.emboj. 7600864

Lanquar, V., Ramos, M. S., Lelièvre, F., Barbier-Brygoo, H., Krieger-Liszkay, A., Krämer, U., et al. (2010). Export of vacuolar manganese by AtNRAMP3 and AtNRAMP4 is required for optimal photosynthesis and growth under manganese deficiency. Plant Physiol. 152, 1986-1999. doi: 10.1104/pp.109. 150946

Lee, S., Jeong, H. J., Kim, S. A., Lee, J., Guerinot, M. L., and An, G. (2010). OsZIP5 is a plasma membrane zinc transporter in rice. Plant Mol. Biol. 73, 507-517. doi: 10.1007/s11103-010-9637-0

Li, S., Zhou, X., Huang, Y., Zhu, L., Zhang, S., Zhao, Y., et al. (2013). Identification and characterization of the zinc-regulated transporters, ironregulated transporter-like protein (ZIP) gene family in maize. BMC Plant Biol. 13:114. doi: 10.1186/1471-2229-13-114

Liedschulte, V., Laparra, H., Battey, J. N. D., Schwaar, J. D., Broye, H., Mark, R., et al. (2017). Impairing both HMA4 homologs is required for cadmium reduction in tobacco. Plant Cell Environ. 40, 364-377. doi: 10.1111/pce. 12870

Lin, Y.-F., Liang, H.-M., Yang, S.-Y., Boch, A., Clemens, S., Chen, C.-C., et al. (2009). Arabidopsis IRT3 is a zinc-regulated and plasma membrane localized zinc/iron transporter. New Phytol. 182, 392-404. doi: 10.1111/j.1469-8137.2009. 02766.x

López-Millán, A.-F., Ellis, D. R., and Grusak, M. A. (2004). Identification and characterization of several new members of the ZIP family of metal ion transporters in Medicago truncatula. Plant Mol. Biol. 54, 583-596. doi: 10.1023/ B:PLAN.0000038271.96019.aa

Lugon-Moulin, N., Zhang, M., Gadani, F., Rossi, L., Koller, D., Krauss, M., et al. (2004). Critical review of the science and options for reducing cadmium in tobacco (Nicotiana tabacum L.) and other plants. Adv. Agron. 83, 111-180. doi: 10.1016/S0065-2113(04)83003-7

Martínez, M., Bernal, P., Almela, C., Vélkez, D., García-Agustín, P., Serrano, R., et al. (2006). An engineered plant that accumulates higher levels of heavy metals than Thlaspi caerulescens, with yields of 100 times more biomass in mine soils. Chemosphere 64, 478-485. doi: 10.1016/j.chemosphere.2005.10.044

McFarlane, H. E., Shin, J. J. H., Bird, D. A., and Samuels, A. L. (2010). Arabidopsis ABCG transporters, which are required for export of diverse cuticular lipids, dimerize in different combinations. Plant Cell 22, 3066-3075. doi: 10.1105/tpc. 110.077974

Menguer, P. K., Farthing, E., Peaston, K. A., Ricachenevsky, F. K., Fett, J. P., and Williams, L. E. (2013). Functional analysis of the vacuolar zinc transporter OsMTP1. J. Exp. Bot. 64, 2871-2883. doi: 10.1093/jxb/ert136

Migocka, M., Papierniak, A., Kosieradzka, A., Posyniak, E., MaciaszczykDziubinska, E., Biskup, R., et al. (2015). Cucumber metal tolerance protein CsMTP9 is a plasma membrane $\mathrm{H}^{+}$-coupled antiporter involved in the $\mathrm{Mn}^{2+}$ and $\mathrm{Cd}^{2+}$ efflux from root cells. Plant J. 84, 1045-1058. doi: 10.1111/tpj.13056

Mills, R. F., Peaston, K. A., Runions, J., and Williams, L. E. (2012). HvHMA2, a P1B-ATPase from barley, is highly conserved among cereals and functions in Zn and Cd transport. PLoS One 7:e42640. doi: 10.1371/journal.pone.0042640

Milner, M. J., Seamon, J., Craft, E., and Kochian, L. (2013). Transport properties of members of the ZIP family in plants and their role in $\mathrm{Zn}$ and Mn homeostasis. J. Exp. Bot. 64, 369-381. doi: 10.1093/jxb/ers315

Miyadate, H., Adachi, S., Hiraizumi, A., Tezuka, K., Nakazawa, N., Kawamoto, T., et al. (2011). OsHMA3, a P1B-type of ATPase affects root-to-shoot cadmium translocation in rice by mediating efflux into vacuoles. New Phytol. 189, 190-199.

Morel, M., Crouzet, J., Gravot, A., Auroy, P., Leonhardt, N., Vavasseur, A., et al. (2009). AtHMA3, a P1B-ATPase allowing $\mathrm{Cd} / \mathrm{Zn} / \mathrm{Co} / \mathrm{Pb}$ vacuolar storage in Arabidopsis. Plant Physiol. 149, 894-904. doi: 10.1104/pp.108.130294

Nakanishi, H., Ogawa, I., Ishimaru, Y., Mori, S., and Nishizawa, N. K. (2006). Iron deficiency enhances cadmium uptake and translocation mediated by the $\mathrm{Fe}^{2+}$ transporters OsIRT1 and OsIRT2 in rice. Soil Sci. Plant Nutr. 52, 464-469. doi: $10.1111 / j .1747-0765.2006 .00055 . x$

Nazri, Z. N., Griffin, J. H. C., Peaston, K. A., Alexander-Weber, D. G. A., and Williams, L. E. (2017). F-group bZIPs in barley - a role in Zn deficiency. Plant Cell Environ. 40, 2754-2770. doi: 10.1111/pce.13045

NCBI Resource Coordinators (2016). Available at: https://blast.ncbi.nlm.nih.gov/ 
Nevo, Y., and Nelson, N. (2006). The NRAMP family of metal-ion transporters. Biophys. Biochim. Acta 1763, 609-620. doi: 10.1016/j.bbamcr.2006. 05.007

Nishida, S., Mizuno, T., and Obata, H. (2008). Involvement of histidine-rich domain of ZIP family transporter TjZNT1 in metal ion specificity. Plant Physiol. Biochem. 46, 601-606. doi: 10.1016/j.plaphy.2008.02.011

Oomen, R. J. F. J., Wu, J., Lelièvre, F., Blanchet, S., Richaud, P., Barbier-Brygoo, H., et al. (2009). Functional characterization of NRAMP3 and NRAMP4 from the metal hyperaccumulator Thlaspi caerulescens. New Phytol. 181, 637-650. doi: 10.1111/j.1469-8137.2008.02694.x

Palmer, C. M., and Guerinot, M. L. (2009). Facing the challenges of Cu, Fe and Zn homeostasis in plants. Nat. Chem. Biol. 5, 333-340. doi: 10.1038/nchembio.166

Park, J., Song, W.-Y., Ko, D., Eom, Y., Hanses, T. H., Schiller, M., et al. (2012). The phytochelatin transporters AtABCC1 and AtABCC2 mediate tolerance to cadmium and mercury. Plant J. 69, 278-288. doi: 10.1111/j.1365-313X.2011. 04789.x

Petschnigg, J., Wolinski, H., Kolb, D., Zellnig, G., Kurat, C. F., Natter, K., et al. (2009). Good fat, essential cellular requirements for triacylglycerol synthesis to maintain membrane homeostasis in yeast. J. Biol. Chem. 284, 30981-30993. doi: 10.1074/jbc.M109.024752

Pighin, J. A., Zheng, H., Balakshin, L. J., Goodman, I. P., Western, T. L., Jetter, R., et al. (2004). Plant cuticular lipid export requires an ABC transporter. Science 306, 702-704. doi: 10.1126/science.1102331

Ramesh, S. A., Shin, R., Eide, D. J., and Schachtman, D. P. (2003). Differential metal selectivity and gene expression of two zinc transporters from rice. Plant Physiol. 133, 126-134. doi: 10.1104/pp.103.026815

Ricachenevsky, F. K., Menguer, P. K., Sperotto, R. A., and Fett, J. P. (2015). Got to hide your $\mathrm{Zn}$ away: molecular control of $\mathrm{Zn}$ accumulation and biotechnological applications. Plant Sci. 236, 1-17. doi: 10.1016/j.plantsci.2015. 03.009

Ricachenevsky, F. K., Menguer, P. K., Sperotto, R. A., Williams, L. E., and Fett, J. P. (2013). Roles of plant metal tolerance proteins (MTP) in metal storage and potential used in biofortification strategies. Front. Plant Sci. 4:144. doi: $10.3389 /$ fpls.2013.00144

Rogers, E. E., Eide, D. J., and Guerinot, M. L. (2000). Altered selectivity in an Arabidopsis metal transporter. Proc. Natl. Acad. Sci. U.S.A. 97, 12356-12360. doi: 10.1073/pnas.210214197

Salamov, A. A., and Solovyev, V. V. (2000). Ab initio gene finding in Drosophila genomic DNA. Genome Res. 10, 516-522. doi: 10.1101/gr.10.4.516

Sano, T., Yoshihara, T., Handa, K., Sato, M. H., Nagata, T., and Hasezawa, S. (2012). "Metal ion homeostasis mediated by Nramp transporters in plant cells - focused on increased resistance to iron and cadmium ion," in Crosstalk and Integration of Membrane Trafficking Pathways, ed. R. Weigert (Rijeka: INTECH), 214-228.

Shingu, Y., Kudo, T., Ohsato, S., Kimura, M., Ono, Y., Yamaguchi, I., et al. (2005). Characterization of genes encoding metal tolerance proteins isolated from Nicotiana glauca and Nicotiana tabacum. Biochem. Biophys. Res. Commun. 331, 675-680. doi: 10.1016/j.bbrc.2005.04.010

Siemianowski, O., Barabasz, A., Weremczuk, A., Ruszczyńska, A., Bulska, E., Williams, L. E., et al. (2013). Development of Zn-related necrosis in tobacco is enhanced by expressing AtHMA4 and depends on the apoplastic $\mathrm{Zn}$ levels. Plant Cell Environ. 36, 1093-1104. doi: 10.1111/pce.12041

Siemianowski, O., Mills, R. F., Williams, L. E., and Antosiewicz, D. M. (2011). Expression of the P1B-type ATPase AtHMA4 in tobacco modifies $\mathrm{Zn}$ and Cd root to shoot partitioning and metal tolerance. Plant Biotechnol. J. 9, 64-74. doi: 10.1111/j.1467-7652.2010.00531.x

Sierro, N., Battey, J. N. D., Ouadi, S., Bakaher, N., Bovet, L., Willig, A., et al. (2014). The tobacco genome sequence and its comparison with those of tomato and potato. Nat. Commun. 5:3833. doi: 10.1038/ncomms4833

Sierro, N., Battey, J. N. D., Ouadi, S., Bovet, L., Goepfert, S., Bakaher, N., et al. (2013). Reference genomes and transcriptomes of Nicotiana sylvestris and Nicotiana tomentosiformis. Genome Biol. 14:R60. doi: 10.1186/gb-201314-6-r60

Sinclair, S. A., and Krämer, U. (2012). The zinc homeostasis network of land plants. Biochem. Biophys. Acta 1823, 1553-1567. doi: 10.1016/j.bbamcr.2012. 05.016

Stephens, B. W., Cook, D. R., and Grusak, M. A. (2011). Characterization of zinc transport by divalent metal transporters of the ZIP family from the model legume Medicago truncatula. Biometals 24, 51-58. doi: 10.1007/s10534-0109373-6

Suh, S. J., Wang, Y.-F., Frelet, A., Leonhardt, N., Klein, M., Forestier, C., et al. (2007). The ATP binding cassette transporter AtMRP5 modulates anion and calcium channel activities in Arabidopsis guard cells. J. Biol. Chem. 282, 1916-1924. doi: 10.1074/jbc.M607926200

Tamura, K., Stecher, G., Peterson, D., Filipski, A., and Kumar, S. (2013). MEGA6: molecular evolutionary genetics analysis version 6.0. Mol. Biol. Evol. 30, 2725-2729. doi: 10.1093/molbev/mst197

Thomine, S., Lelievre, F., Debarbieux, E., Schroeder, J. I., and Barbier-Brygoo, H. (2003). AtNRAMP3, a multispecific vacuolar metal transporter involved in plant response to iron deficiency. Plant J. 34, 685-695. doi: 10.1046/j.1365313X.2003.01760.x

Ueno, D., Yamaji, N., Kono, I., Huang, C. F., Ando, T., Yano, T., et al. (2010). Gene limiting cadmium accumulation in rice. Proc. Natl. Acad. Sci. U.S.A. 107, 16500-16505. doi: 10.1073/pnas.1005396107

Vangronsveld, J., Herzig, R., Weyens, N., Boulet, J., Adriaensen, K., Ruttens, A., et al. (2009). Phytoremediation of contaminated soils and groundwater: lessons from the field. Environ. Sci. Pollut. Res. 16, 765-794. doi: 10.1007/s11356-0090213-6

Vera-Estrella, R., Gómez-Méndez, M., Amezcua-Romero, J. C., Barkla, B. J., Rosas-Santiago, P., and Pantoja, O. (2017). Cadmium and zinc activate adaptive mechanisms in Nicotiana tabacum similar to those observed in metal tolerant plants. Planta 246, 433-451. doi: 10.1007/s00425-0172700-1

Verret, F., Gravot, A., Auroy, P., Leonhardt, N., David, P., Nussaume, L., et al. (2004). Overexpression of AtHMA4 enhances root-to-shoot translocation of zinc and cadmium and plant metal tolerance. FEBS Lett. 576, 306-312. doi: 10.1016/j.febslet.2004.09.023

Verrier, P. J., Bird, D., Burla, B., Dassa, E., Forestier, C., Geisler, M., et al. (2008). Plant ABC proteins - a unified nomenclature and updated inventory. Trends Plant Sci. 13, 151-159. doi: 10.1016/j.tplants.2008.02.001

Vert, G., Grotz, N., Dédaldéchamp, F., Gaymard, F., Guerinot, M. L., Briat, J.-F., et al. (2002). IRT1, an Arabidopsis transporter essential for iron uptake from the soil and for plant growth. Plant Cell 14, 1223-1233. doi: 10.1105/tpc. 001388

Wang, Y., Liu, H., Wang, S., Li, H., and Xin, Q. (2015). Overexpressing of a novel wheat prolyl aminopeptidase gene enhances zinc stress tolerance in transgenic Arabidopsis thaliana. Plant Cell Tiss. Organ Cult. 121, 489-499. doi: 10.1007/ s11240-015-0719-1

Weber, M., Harada, E., Vess, C., Roepenack-Lahaye, E. V., and Clemens, S. (2004). Comparative microarray analysis of Arabidopsis thaliana and Arabidopsis halleri roots identifies nicotianamine synthase, a ZIP transporter and other genes as potential metal hyperaccumulation factors. Plant J. 37, 269-281. doi: 10.1046/j.1365-313X.2003.01960.x

Williams, L. E., and Mills, R. F. (2005). P1B-ATPase - an ancient family of transition metal pumps with diverse functions in plants. Trends Plant Sci. 10, 491-502. doi: 10.1016/j.tplants.2005.08.008

Williams, L. E., Pittman, J. K., and Hall, J. L. (2000). Emerging mechanisms for heavy metal transport in plants. Biochem. Biophys. Acta 1465, 104-126. doi: 10.1016/S0005-2736(00)00133-4

Wojas, S., Clemens, S., Hennig, J., Skłodowska, A., Kopera, E., Schat, H., et al. (2008). Overexpression of phytochelatin synthase in tobacco: distinctive effects of AtPCS1 and CePCS genes on plant response to cadmium. J. Exp. Bot. 59, 2205-2219. doi: 10.1093/jxb/ern092

Wojas, S., Hennig, J., Plaza, S., Geisler, M., Siemianowski, O., Skłodowska, A., et al. (2009). Ectopic expression of Arabidopsis ABC transporter MRP7 modifies cadmium root-to-shoot transport and accumulation. Environ. Pollut. 157, 2781-2789. doi: 10.1016/j.envpol.2009.04.024

Wojas, S., Ruszczyńska, A., Bulska, E., Wojciechowski, M., and Antosiewicz, D. M. (2007). $\mathrm{Ca}^{2+}$-dependent plant response to $\mathrm{Pb}^{2+}$ is regulated by LCT1. Environ. Pollut. 147, 584-592. doi: 10.1016/j.envpol.2006. 10.012

Wong, C. K. E., and Cobbett, C. S. (2009). HMA P-type ATPases are the major mechanism for root-to-shoot Cd translocation in Arabidopsis thaliana. New Phytol. 181, 71-78. doi: 10.1111/j.1469-8137.2008.02638.x

Yamaji, N., Sasaki, A., Xia, J. X., Yokosho, K., and Ma, J. F. (2013). A node-based switch for preferential distribution of manganese 
in rice. Nat. Commun. 4, 2442-2453. doi: 10.1038/ncomms 3442

Yoshihara, T., Hodoshima, H., Miyano, Y., Shoji, K., Shimada, H., and Goto, F. (2006). Cadmium inducible Fe deficiency responses observed from macro and molecular views in tobacco pants. Plant Cell Rep. 25, 365-373. doi: 10.1007/ s00299-005-0092-3

Zientara, K., Wawrzyńska, A., Łukomska, J., López-Moya, J. R., Liszewska, F., Assunção, A. G. L., et al. (2009). Activity of the AtMRP3 promoter in transgenic Arabidopsis thaliana and Nicotiana tabacum plants is increased by cadmium, nickel, arsenic, cobalt and lead but not by zinc and iron. J. Biotechnol. 139, 258-263. doi: 10.1016/j.jbiotec.2008.12.001
Conflict of Interest Statement: The authors declare that the research was conducted in the absence of any commercial or financial relationships that could be construed as a potential conflict of interest.

Copyright (c) 2018 Papierniak, Kozak, Kendziorek, Barabasz, Palusińska, Tiuryn, Paterczyk, Williams and Antosiewicz. This is an open-access article distributed under the terms of the Creative Commons Attribution License (CC BY). The use, distribution or reproduction in other forums is permitted, provided the original author(s) and the copyright owner are credited and that the original publication in this journal is cited, in accordance with accepted academic practice. No use, distribution or reproduction is permitted which does not comply with these terms. 